\title{
PRESENCIA Y SIGNIFICADO DEL ORGANERO FELIPE URARTE EN LA PROVINCIA DE VALLADOLID DURANTE LA PRIMERA MITAD DEL SIGLO XVIII
}

\author{
PRESENCE AND MEANING OF THE ORGAN BUILDER FELIPE URIARTE \\ IN THE PROVINCE OF VALLADOLID DURING \\ THE FIRST HALF OF THE EIGHTEENTH CENTURY
}

José Ignacio Palacios Sanz

Universidad de Valladolid

\begin{abstract}
Resumen
La actividad organera en la provincia de Valladolid tuvo uno de los momentos más álgidos a comienzos del siglo XVIII con Felipe Urarte, maestro que incorpora los avances aparecidos en los últimos años del seiscientos, y que podemos ver y escuchar en los órganos de Tordesillas, fundamentalmente, Medina del Campo, Pozaldez y Olmedo.

\footnotetext{
Artesano, lengüetería, ecos, estaño, disposición, secreto, fue-
}

Palabras clave lles.
\end{abstract}

\section{INTRODUCCIÓN}

Felipe Urarte posiblemente sea un referente necesario para entender la organería castellana durante la primera mitad del siglo XVIII. Aunque las primeras noticias sobre este organero de origen navarro se remontan treinta años atrás, poco a poco nuevas aportaciones han ido arrojando datos, fundamentalmente a partir de los estudios de Labeaga ${ }^{1}$, Jam-

1 LABEAGA MENDIOLA, 102 (Logroño, 1982): 125-131; LABEAGA MENDIOLA, 4, (San Sebastián, 1988): 27-77, y LABEAGA MENDIOLA, 5 (San Sebastián, 1991): 41.

\begin{abstract}
Organero activity in the province of Valladolid had one of the moments more algid at the beginning of the 18th century with Felipe Urarte, that adds the advances that had appeared in last years of the six hundred, and that can see and listen to in Tordesillas organs, fundamentally, Medina del Campo, Pozaldez and Olmedo.
\end{abstract}

Key words

Craftsman, chamade, pipe organ, echos, disposition; windchest, bellows.

bou², Jesús Ángel de la Lama ${ }^{3}$, Luciano Reinoso Robledo ${ }^{4}$. También encontramos información en el Catálogo Monumental de la provincia de Valladolid ${ }^{5}$, en los catálogos de órganos de La Rioja y Álava, a cargo de José Santos de la

2 JAMBOU (1988): vol. II, 142-143 y 153; (2002): vol. 10, 549. 3 LAMA (1981): 61-62.

4 REINOSO ROBLEDO (1991): tomo II, 1172, 1201-1203, 1211-1213, 1342, 1401-1409 y 1638-1639.

5 MARTÍN GONZÁLEZ (1973): tomo VI, 102 y 108, ARA GIL y PARRADO DEL OLMO (1980): tomo XI, 218, 234 y 237, y MARCOS VILLÁN y FRAILE GÓMEZ (2003): 164-165. 
Iglesia $^{6}$, y la tesis que realizamos sobre Soria ${ }^{7}$. La última contribución ha sido la reciente restauración del órgano de la parroquia de Santa María del de Tordesillas ${ }^{8}$. Además hay un interesante número de obras en varias provincias de la comunidad, que han servido para redescubrir la figura de tan destacado organero.

\section{FAMILIAS OLITE-URARTE}

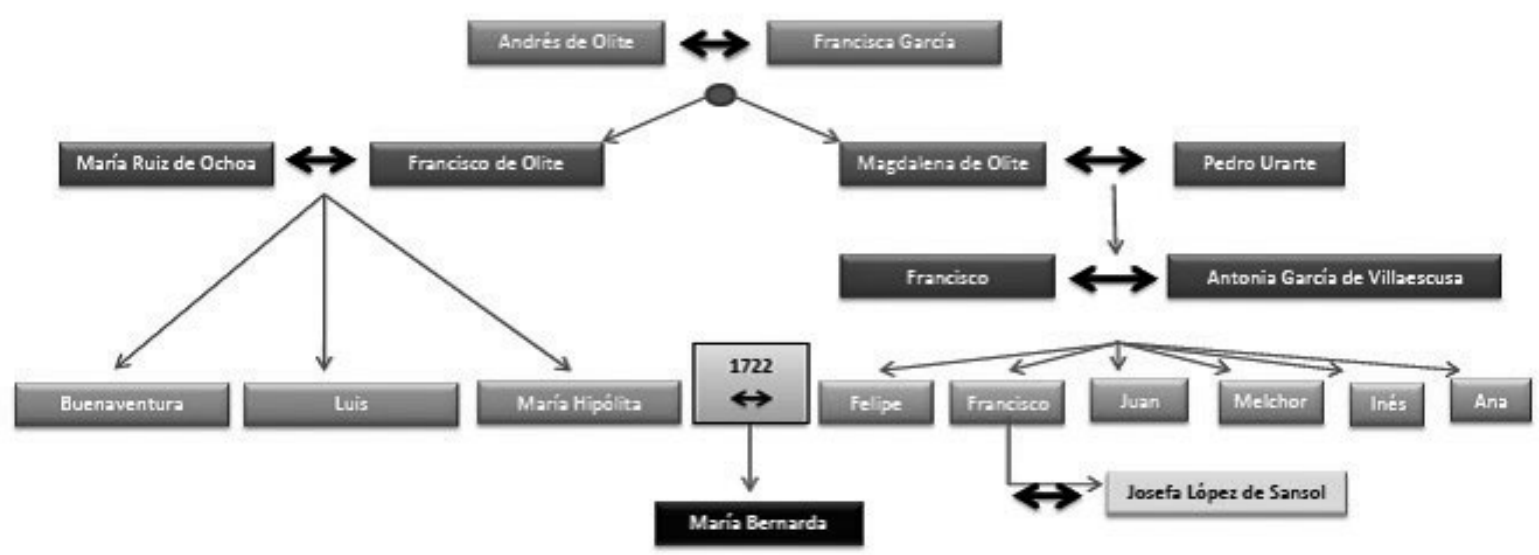

Figura 1. Árbol genealógico de las familias Olite y Uriarte

\section{BIOGRAFÍA DE FELIPE DE URARTE (1685-1747)}

Nació en el pueblo de Viana (Navarra) en 1685, y fue bautizado en la parroquia de San Pedro el 30 de abril de 1685. Era hijo del matrimonio formado por Francisco Urarte y Antonia García de Villaescusa, junto a sus otros cinco hermanos Juan, Melchor, Inés, Ana y Francisco, siendo este último, organero también, y cinco años menor que Felipe?

6 IGLESIA UGARTE (1991): 182, e IGLESIA UGARTE (1997): 187-192.

7 PALACIOS SANZ (1994): 199-200.

8 LAMA (1981): 346-348, PALACIOS SANZ (2008): vol. I, 7891. NIETO MIGUEL (2009): 150, y http://www.organaria.es (última consulta 19 noviembre de 2011).

9 IGLESIA UGARTE (1997): 33, 54, 174-176, y 187. Con Francisco fabricó los órganos de Labastida (1756), Elciego (1757) y Salvatierra (1762).
La ciudad de Viana fue una ciudad con una larga tradición de artesanos desde mediados del siglo XVII, que se remontan a Juan de Tabar, formado en Lerín pero establecido en Viana ${ }^{10}$ y a su hijo Juan Bautista Tabar ${ }^{11}$. A él le suceden su discípulo Francisco Olite y los dos hermanos Urarte $^{12}$. Felipe aprendió el oficio durante cinco años, entre 1701 a 1706, bajo la tutela de su tío por vía de su abuela materna, Francisco de Olite (en otros casos este periodo de formación oscilaba de tres a nueve años) ${ }^{13}$, primero como

10 ZUDAIRE HUARTE, IX-2 (Madrid, 1986): 411-412.

11 JAMBOU, vol. II, 1 (Madrid, 1979): 28-30; ZUDAIRE HUARTE, 160-161 (Pamplona, 1980): 534-535; LABEAGA MENDIOLA, 158-159 (Pamplona, 1980): 226; LABEAGA MENDIOLA, 5 (San Sebastián, 1991): 41, y JAMBOU (1988): vol. II, 56.

12 LABEAGA MENDIOLA, 5 (San Sebastián, 1991): 27.

13 LABEAGA MENDIOLA, 5 (San Sebastián, 1991): 42, 53 y 63. Juan de Tabar contrajo matrimonio con Catalina Martínez, vecina de Viana, en 1688, lo cual ya explica las relaciones mutuas entre estas 
aprendiz siendo huérfano de dieciséis años, a cambio, según el contrato firmado el 4 de septiembre de 1701, aparte de otros aspectos económicos y disciplinarios: no faltar ningún día, recibir el alimento y recibir los vestidos necesarios. De esta forma, personifica también la herencia del artesano que aprende un oficio de forma reglada y jerarquizada.

Al finalizar esta etapa marcha de Viana a servir al rey "en las armas", dejando antes testamento y "como cabezalero a Francisco Olite" 14 , que estaba inmerso por entonces, en concreto en 1710, en el órgano de la catedral de Santo Domingo de La Calzada ${ }^{15}$.

En 1722 regresa a Viana para contraer nupcias con María Hipólita, hija de su maestro Olite, en la misma iglesia de San Pedro, y así consolidar el linaje familiar ${ }^{16}$. De este matrimonio tuvo una hija, llamada María Bernarda ${ }^{17}$.

Hizo de nuevo testamento en 1729, antes de volver a partir al reino de Castilla, una vez que hubo finalizado las obras del órgano de la parroquia de San Pedro de Viana. Regresó a su tierra natal, hacia los años cuarenta, después del último periplo castellano, en donde morirá el 8 de julio de $1747^{18}$.

\section{ETAPAS CONSTRUCTIVAS EN LA OBRA DE URARTE Y SU CONTEXTO}

Se pueden diferenciar hasta tres etapas constructivas en la producción de Felipe Urarte; una inicial de formación hasta los 25 años, para, a continuación, realizar un primer acercamiento al corazón de Castilla a través de la provincia de Segovia, pasando por Soria, antes de llegar a Valladolid, periodo que dura de 1712 a 1723 ; una segunda, en la que regresa a su tierra natal para casarse, con trabajos muy puntuales, como los que realiza en Cuenca y Veles, y después, alrededor de 1730, inicia una nueva etapa en Castilla desde el pueblo soriano de Borobia, pasando por Puras y dejando el camino abierto a su hermano Francisco en el pueblo palentino de Villada, en 1739, siguiendo los pasos emprendidos por Francisco de Olite en Torquemada ${ }^{19}$, y que tiene como

dos villas y las influencias organeras por vía de parentesco entre él y los artesanos Juan Tabar, Francisco Olite y Felipe Urarte. A su vez, Tabar ya está presente en Valladolid a finales del siglo XVII, y en la catedral de Burgos, en 1679. MATESANZ DEL BARRIO, 207 (Burgos, 1993/2): 311. También están confirmados sus trabajos en Navalcarnero y en la catedral de Sigüenza, véase MARCO MARTÍNEZ (1990): 24.

14 LABEAGA MENDIOLA, 5 (San Sebastián, 1991): 43. 15 SÁEZ DE OCÁRIZ Y RUIZ DE AZÚA (2001): 182. 16 LABEAGA MENDIOLA, 5 (San Sebastián, 1991): 43. 17 LABEAGA MENDIOLA, 5 (San Sebastián, 1991): 41, y JAMBOU (1988): vol. I, 56.

18 LABEAGA MENDIOLA, 5 (San Sebastián, 1991): 49. 19 BARBIER RAMOS (2008): 430 y 447. colofón el retorno a Viana para ejecutar los compromisos de Álava y el postrero de Haro.

La actividad de Urarte en Valladolid fue fecunda. De las veintitrés actuaciones en Castilla y León, once corresponden a esta provincia, exactamente entre los años 1715 a 1722 , y de 1731 a $1732^{20}$. También es un claro ejemplo de organero de comienzos de siglo, que se desplaza de norte a sur, traspasando las fronteras de su región en busca de un amplio radio de acción, que en su caso incluye iglesias parroquiales, y abarcando una amplia zona de más de trescientos kilómetros, que va de Soria a Zamora y de Segovia a Palencia ${ }^{21}$, pero teniendo el epicentro entre la zona comprendida entre Olmedo y Tordesillas, en donde montó un taller estable durante bastantes años. Si bien, la única incursión fuera de este ámbito de acción habitual se produce en la colegiata de Santa María La Mayor de Toro, en 1723, para añadir dos registros al órgano y afinarle ${ }^{22}$. De igual modo, tenemos el precedente del sangüesino Jaime de Sola, que tal vez aprendió el oficio en Zaragoza ${ }^{23}$, y que ya había iniciado ese mismo camino años antes, en concreto, en 1664, para residir en Segovia, y con varias actuaciones en ella, aparte de Zamora, en 1676, y Medina de Rioseco, en $1683^{24}$. Asimismo, Urarte es un claro ejemplo, en palabras de Jambou, de la descentralización de los focos organeros entrono a las sedes catedralicias o colegiales ${ }^{25}$, a raíz de la ley emitida por Felipe V en 1723 (Título XIV), como aplicación del Decreto de Nueva Planta de 1707, en la que derogaba la norma por la que los cargos civiles o religiosos no podían ocupar estos puestos y prebendas si no eran castellanos de nacimiento ${ }^{26}$, si bien la norma en realidad no se cumplió en el mundo del órgano, ya que los organeros "gozaban de plena libertad de desplazamiento para el ejercicio de su profesión" $" 27$.

Para el inicio de la obra de cualquier instrumento era preceptiva la aprobación y permiso del visitador o del gober-

20 PALACIOS SANZ (2008): vol. I, 78.

21 JAMBOU, vol. II, 1 (Madrid, 1979): 23. Los diez maestros que tiene estudiados llegaron, entre 1663 a 1700, por el este hasta Sigüenza, y por el oeste a Oviedo.

22 FLÓREZ SANTIAGO (2003): 348-355, y Toro, Colegiata de Santa María La Mayor, Libro de Cuentas de Fábrica 1716-1727, Data 1723, Archivo Diocesano de Zamora: f. 157 v.

23 JAMBOU, vol. II, 1 (Madrid, 1979): 30.

24 Protocolos, 1663, Archivo Histórico Provincial de Valladolid (AHPVa), Sig. 8958: f. 564-566 v.; JAMBOU (1988): vol. I, 30, y REINOSO ROBLEDO (1991): tomo III, 2369-2373.

25 JAMBOU (1988): vol. I, 177.

26 Novísima recopilación de las leyes en España. Dividida en XII libros. Mandado formar por el señor don Carlos IV, 1805, tomo II: 13; ÁLVAREZ-VALDÉS y VALDÉS (1992): 559; TORRENTE, 12, (Granada, 1996-97): 234, y PALACIOS SANZ (2001): vol. II, 920. 27 JAMBOU (1988): vol. I, 4. 
nador eclesiástico y que la iglesia tuviera caudales suficientes para acometer las obras, aunque en alguna ocasión las donaciones de la feligresía permitían juntar las cantidades que se requerían, como sucede en Sepúlveda ${ }^{28}$. El siguiente paso era realizar el contrato firmado por las partes y rubricado ante notario.

Normalmente los maestros adoptaban un prototipo en la mayoría de los casos siguiendo la estética del momento y patrones estereotipados, tanto en la caja -así sucede en Prádena de la Sierra y Sepúlveda, en la provincia de Segovia, y en Olmedo y Pozaldez, en Valladolid, como con el material sonoro. Todo el conjunto se adoptaba a las exigencias de la parte contratante ${ }^{29}$, el presupuesto, las exigencias de la parroqia y el espacio arquitectónico, produciéndose una dicotomía entre ambos parámetros, aunque en la mayoría de los casos priorizaba el segundo ${ }^{30}$. Era habitual encontrar tres tamaños de instrumentos, de cinco a ocho juegos (Pedraza de la Sierra), unos intermedios con diez registros (Olmedo) y los más grandes alcanzan dieciocho (Santa María de Tordesillas).

Para realizar la caja contratan a maestros locales, hechas en madera de pino de Soria, junto con paneles en nogal y roble, abundante talla y adornos barrocos, calados y dorados, y con los costados lisos. La fachada se divide en tres cuerpos, que se ensanchan desde el inferior hasta la coronación, con ménsulas y cornisas e intercolumnios con motivos vegetales y guirnaldas. Los instrumentos pequeños poseen tres calles, cinco los intermedios, y siete los de mayor tamaño, siendo la calle central la más alta, y rematada por cartelones de forma trapezoidal, además de poner niños trompeteros en los cubos. Las medidas del mueble oscilan entre los 4,30 mts. y los $5 \mathrm{mts}$. de altura, por 2,50 mts. de ancho y más uno de fondo ${ }^{31}$, como así sucede en Puras, según describe el propio organero en el proyecto con todo lujo de detalles, tanto en el ancho como en el alto, con medidas de pies y cuartas ${ }^{32}$. No falta la decoración de dorados sobre preparación cálcica, y los policromados al temple sobre estuco en tonos azules, verdes, ocres y rojos ${ }^{33}$. El precio del mueble es siempre era menor al del instrumento. Tomando como referencia el del pueblo soriano de Borobia -en la actualidad órgano desaparecido y posiblemente con una caja pequeña y sin ornato-, el precio del mueble ascendió a 407 reales, fren-

28 REINOSO ROBLEDO (1991) tomo II, 1403.

29 JAMBOU (1988) vol. I, 194, y REINOSO ROBEDO (1991): tomo II, 1639.

30 JAMBOU (1998): 86.

31 REINOSO ROBEDO (1991): tomo II, 1211, 1342 y 1407.

32 Protocolos, 1716, AHPVa, Sig. 5446: f. 122-123 v. y PALACIOS SANZ (2008): vol. I, 116.

33 ACITORES (2008): vol. I, 122, y BERMEJO (2011): 3-4. te a los más de dos mil reales de la caja de Santa María de Tordesillas. En cambio, la tubería, mecánica, fuelles y secretos en Borobia cuestan diez veces más, 4.353 reales, entrono a 5.000 reales en las tres actuaciones de Segovia ${ }^{34}, 6.000$ reales en la iglesia de Santa María de Viana ${ }^{35}$, y en Tordesillas el precio se eleva a 9.750 reales de vellón ${ }^{36}$. A estos gastos hay que añadir el transporte de los materiales con caballerías y carros (en Borobia desde la ciudad de Soria), el montaje del órgano por ocho oficiales y un mes para la caja, además de los gastos de estancia en posadas, leña y manutención (de nuevo en el caso borobiense, por 52 días y en Pedraza de la Sierra por 54 días). Por último, la peritación por uno o dos organistas u organeros con dietas de viaje y estancia, suma un total de 461,46 reales o 6 doblones ${ }^{37}$.

En más de una ocasión, como consta en Pedraza, Prádena de la Sierra ${ }^{38}$, y Tordesillas, mientras apea a inicia la construcción del órgano, alguna otra parroquia de la misma o de localidades cercanas contactan con el organero para que repare su órgano. Así sucedió con Felipe Urarte en Tordesillas en las dos parroquias de San Pedro, en 1721, y Santiago $^{39}$, y en el convento de dominicos de Santo Tomás, en donde aún le debía en 1722, fray Mateo Galán, 400 reales $^{40}$.

Urarte es heredero de las técnicas constructivas de los organeros vascos-navarros, Andueza o Mendoza, ambos procedentes de Lerín ${ }^{41}$. Como era habitual en las capitulaciones, se detallan con precisión los elementos, materiales y componentes del órgano: la calidad de los juegos, el secreto, los teclados y fuelles ${ }^{42}$. Para la tubería, empleará estaño de Inglaterra en proporción de mezcla de quince arrobas de estaño y diez de plomo ${ }^{43}$ y para las lengüetas usa "latón morisco o dorado de Berbería" ${ }^{44}$. Los secretos son de pino de Soria con sus tapas, varillas mesa y correderas de nogal, con 42 ó 45 canales -así lo expresa en todos su contratos-, aunque el teclado más amplio lo incorpora tardíamente y se muestra algo retardatario en este aspecto (constan de 42 notas los órganos

34 REINOSO ROBEDO (1991): tomo II, 1203, 1403 y 1639. 35 LABEAGA MENDIOLA, 4 (San Sebastián, 1988): 39-41. 36 Libro de Carta-Cuenta (1712-1756), Data 1712-1714, s.f., y Data 1720-1722, s.f., y AHPVa: Protocolos, Sig. 5446, f. 118.

37 Libro de Carta-Cuenta (1712-1756), Data 1715-1717, Archivo Parroquial de Borobia (APBO): s.f., y REINOSO ROBLEDO (1991): tomo II, 1203.

38 REINOSO ROBLEDO (1991): tomo II, 1172.

39 PALACIOS SANZ (2008): 83-84.

40 LABEAGA MENDIOLA, 5 (San Sebastián, 1991): 44, y PA-

LACIOS SANZ (2008): 85.

41 LABEAGA MENDIOLA, 160-161 (Pamplona, 1980b): 523. 42 SAURA BUIL (2001): 444.

43 LABEAGA MENDIOLA, 5 (San Sebastián, 1991): 27-28.

44 LABEAGA MENDIOLA, 102 (Logroño, 1982): p. 125; LABEAGA MENDIOLA, 5 (San Sebastián, 1991): 49, y LABEAGA MENDIOLA, 4 (San Sebastián, 1988): 41. 
de Santa María de Tordesillas, Sepúlveda, Santa María La Real de Nieva y Prádena de la Sierra, y de 45 Pozaldez $)^{45}$. Suele colocar tres fuelles de marca mayor con siete pliegues con los tableros de pino, guarnecidos con baldreses al "estilo moderno", accionados con palancas, con su caballete y conductos forrados de papel y embetunados con cola y estopa. Los tirantes de los registros tienen las cabezas de boj para abrir a "la mano", y en el teclado las notas naturales está fabricadas en boj o hueso y en ébano o nogal las alteraciones $\mathrm{o}$ alzas, con las reducciones y varillas que caen "a plomo"

El modelo sonoro diseñado para Santa María de Tordesillas lo sigue repitiendo, al igual que hacían otros maestros del momento ${ }^{47}$, aún en 1722 en su pueblo natal de Via$n^{48}$, y más tarde, en 1732, en Puras ${ }^{49}$, con las variantes del Tapadillo en lugar del Nasarte en docena, y el Nasardo en quincena, en lugar de la Sexquiáltera, que suponen un primer acercamiento al coro de nazardos, como complemento a los tapados, y que en estos órganos se concibe más bien como un juego solista. Es más, en la ampliación de Viana, incorpora el mismo esquema de la lengüetería de Tordesillas, siguiendo claramente los dictámenes estético-sonoros del seiscientos y la fisonomía de la caja: Trompeta real interior para ambas manos, Bajoncillo-Clarín, Chirimía-Trompeta magna (el precio de este juego completo era de 600 reales $^{50}$ ) y Dulzaina completa. Los canales para la zoquetería van tallados en la misma caja y el aire es conducido por tablones ensamblados y no perforados, que se ubican por debajo del secreto. Urarte emplea la fórmula de presentar el Bajoncillo de $6^{1 / 2}$ colocado en el centro o en un lado de la fachada, como compañero del Clarín de 8 pies, ambos de "mediamano" 51 , si bien fray Joseph de Echeverría lo había implantado en 1659, y después lo estandarizan los Mendoza y Mañeru, apareciendo de forma estandarizada en las fachadas hasta finales del siglo $\mathrm{XIX}^{52}$. Ambos pueden tocarse juntos o agrupados ${ }^{53}$. También pone la Trompeta magna de 16 pies en los tiples del exterior,

45 REINOSO ROBLEDO (1991): tomo II, 1212, 1342 y 1409, y PALACIOS SANZ (2008): tomo I, 80-82.

46 LABEAGA MENDIOLA, 2 (San Sebastián, 1985): 14-16; LABEAGA MENDIOLA, 5 (San Sebastián, 1991): 40-41, y 46.

47 Hacia el primer tercio de siglo los organeros suele suprimir el Tapadillo para dar cabida a los tres juegos de Nasardos en docena, quincena y decisetena. También emplean junto a la Chirimía el Oboe en ambas manos, registro que no suele coloca Urarte. Véase LABEAGA MENDIOLA, 209 (Pamplona, 1996): 511, y LABEAGA MENDIOLA, vol. 9, 1 (Madrid, 1986): 81-82 y 87-89.

48 LABEAGA MENDIOLA, 5 (San Sebastián, 1991): 44-45.

49 PALACIOS SANZ (2008): tomo I, 114.

50 LABEAGA MENDIOLA, 102 (Logroño, 1982): 130.

51 Protocolos, 1714, AHPVa, Sig. 9458: f. 515.

52 ZUDAIRE, VII-2 (1984): 77-79, y LAMA (1995c): 569.

53 LAMA (1995c): 563. denominación que había recibido a mediados del siglo XVII con Domingo Aguirre ${ }^{54}$. A su lado completan los bajos la Chirimía en quincena, de caño estrecho para hacer de solista y que patentó el organero navarro Joseph Mañeru ${ }^{55}$, y que se sistematiza en sus órganos desde $1695^{56}$. Y por debajo de este complejo sonoro, aparece la Dulzaina "en el canto del secreto" y con "su cepo muy asegurado", como afirma Gregorio González Roldán en Medina de Rioseco ${ }^{57}$, con los boquetes de plomo y bronce para los canales y lenguas, como ya lo empleaba Olite unos años atrás ${ }^{58}$. El aspecto visual de todo este conjunto sonoro en las fachadas resulta de absoluta simetría y ornato.

Todos los órganos de Urarte tienen como base un Flautado de 13 con cuerpo, al que se superpone en la pirámide sonora la Octava, y la Docena, a las que se da el epíteto de "clara", y por encima dobla la Quincena, como en Olmedo, y después asoma la Decinovena, y una tercera octava aguda o Ventidosena, que en realidad corresponde a un Lleno, siguiendo modelos del siglo XVII, en donde, tanto en Tordesillas como en Pozaldez, tiene tres hileras. Culmina la pirámide sonora la Címbala de igual número de filas ${ }^{59}$.

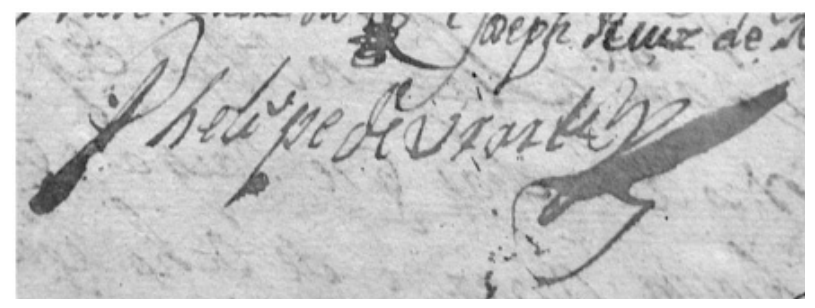

Figura 2. Firma de Felipe Urarte en 1716 (Archivo Histórico Provincial Valladolid)

Al mismo tiempo, incorpora las novedades aplicadas por Domingo Mendoza en las dos cornetas, quien ya propuso en 1695 encerrar una en un cajón, activada la apertura de la tapa suprior con un estribo accionado por el pie, y llamada Corneta en eco, como elemento totalmente barroquizante $^{60}$. Consta de seis caños, en un secretillo por encima del principal y que se contrapone y dialoga con la Corneta real, que a su vez posee toda la serie armónica con siete tubos

54 JAMBOU (1988): vol. II, 99 y 112, y LAMA (1995 ): 296. 55 DONOSTIA, 10 (Barcelona, 1955): 131; SAGASETA y TABERNA (1985): 303, LAMA (1995c): 609 y 666.

56 LAMA (1995a): 296.

57 Protocolos, 1717, AHPVa, Sig. 9461: f. 247.

58 LABEAGA MENDIOLA, 5 (San Sebastián, 1991): 39.

59 LAMA (1995b): 191.Francisco Ortega sigue esta misma denominación, pero aumenta en una fila más ambos juegos compuestos. 60 JAMBOU (1988): vol. I, 252. 
por nota ${ }^{61}$. La Corneta de Eco tuvo una amplia difusión y llegó a ser un registro omnipresente en muchos maestros, y algo imprescindible para los mismos organistas ${ }^{62}$. Así acontece con otros maestros coetáneos que trabajan por tierras vallisoletanas: Antonio Pérez, en 1714, propone ponerla en el órgano de la iglesia de Santiago, y Francisco Ortega, en 1728, en Santa María, ambos en la villa de Medina de Rioseco ${ }^{63}$. Posee dos planos sonoros, eco y contraeco, gracias al movimiento de apertura y cierre de la tapa superior. Necesariamente se acompaña con el Tapadillo de mano izquierda, como así declara Ortega en el documento notarial para el precitado órgano riosecano ${ }^{64}$.

No faltarán los juegos de adorno, incluso en los órganos pequeños, en los que siempre son accionados con dos o tres pisas, como son los Cascabeles, registro festivo y que ya utilizó el monje Echeverría ${ }^{65}$, los Tambores en Delasolre, y los Timbales en Alamire ${ }^{66}$. Al mismo tiempo y por estos años de comienzos de siglo empieza a aparecer incorporados los nombres de estos registros en los títulos de las obras para órgano. Son dignos de mención Juan de Cabanilles y el franciscano Martin i Coll ${ }^{67}$.

Mantuvo una relación de amistad con otros colegas, especialmente con Diego de Orio Tejada, organero natural de Ocón ${ }^{68}$. Trabajó como aprendiz con Bruno de Guriezo hacia 1689 pero dos años después lo encontramos a las órdenes de Francisco Olite en Ezcaray ${ }^{69}$. Orio fue quien supervisó el órgano de Santa María de Tordesillas ${ }^{70}$, además de levantar de nueva planta el de convento de Nuestra Señora de Arnedo, Baños de Río Tobía, Murillo de Río Leza, Santa María La Mayor de Treviana, San Miguel de Ocón, Lumbreras de Cameros $^{71}$, Ezcaray ${ }^{72}$ y Covarrubias ${ }^{73}$, y reformar el órgano de la catedral de El Burgo de Osma, en $1721^{74}$. Adquirió gran notoriedad en Sevilla en donde falleció ${ }^{75}$. También dio garantía a estas realizaciones de Urarte. Otro caso similar es Félix de Yoldi, que fue tasador en el órgano de Arella-

61 LAMA (1995c): 409.

62 BARRERO BALADRÓN y GRAAF, de, (2004): 142.

63 GARCÍA CHICO, XI (Barcelona, 1956): 199 y 204.

64 Protocolos, 1728, AHPVa, Sig. 9263: f. 193.

65 LAMA (1995d): 741.

66 LABEAGA MENDIOLA, 2 (San Sebastián, 1985): 14-16.

67 MARTÍN i COLL (1984): 200-206.

68 RUBIO, 1 (Ocón, 2000): 20.

69 PÉREZ IRACHETA, 2 (Santo Domingo de la Calzada, 2006): 37 y 39 .

70: Protocolos, 1716, AHPVa, Sig. 5446: f. 99-100

71 SALAS FRANCO (1994): 50-52. y 165 .

72 RODRÍGUEZ SUSO, 3 (Cerdanyola del Vallès, 1983): 151

73 SAENZ TERREROS, 2 (Burgos, 1981): 282.

74 PALACIOS SANZ (1994): 237.

75 AYARRA JARNE (1974): 83 y 97. no (Navarra), a pesar de aunque de haber mantenido pleitos con su suegro en la Real Corte de Navarra y en el tribunal eclesiástico ${ }^{76}$. También es obligado citar en estas tareas de peritación a Ramón de Tarazona, organero vecino de Pamplona $^{77}$, y a José de Mañeru, en Santa María de Viana ${ }^{78}$, con el que mantuvo una relación de amistad, incluso le dio poderes de representación notarial ${ }^{79}$. Todos son representantes de la organería del primer tercio del siglo XVIII, a la postre la primera época dorada del órgano barroco español.

\section{RELACIÓN DE ÓRGANOS DE NUEVA PLANTA Y RESTAURACIONES DE FELIPE URARTE ${ }^{80}$}

- Pedraza de la Sierra (Segovia), iglesia de San Juan, $1712, \mathrm{~N}$

- Prádenas (Segovia), iglesia de San Martín obispo, $1712, \mathrm{~N}$

- Almazán (Soria), iglesia de Santa María del Campanario, 1713, I

- Serón de Nágima (Soria), iglesia de Santa María del Mercado, 1714, N

- Olmedo (Valladolid), convento jerónimo de La Mejorada, 1715, I

- Borobia (Soria), iglesia de Nuestra Señora de la Asunción, 1716, N

- Pozaldez (Valladolid), iglesia de Santa María, 1717, N

- Sepúlveda (Segovia), santuario de Nuestra Señora de la Peña, $1717, \mathrm{~N}$

- Moraleja de las Panaderas (Valladolid), iglesia de San Boal, 1718, I

- Tordesillas (Valladolid), iglesia de Santa María, $1718, \mathrm{~N}$

- Tordesillas (Valladolid), convento de Santo Tomás o de dominicos, 1720, I

-Tordesillas (Valladolid), iglesia de Santiago, 1721, N

- Tordesillas (Valladolid), iglesia de San Pedro, 1721, I

- Medina del Campo (Valladolid), convento de San Andrés, 1721, I

- Toro (Zamora), convento de San Ildefonso, 1721, N

- Medina del Campo (Valladolid), iglesia de San Miguel, 1722, I

- Simancas (Valladolid), iglesia de El Salvador, 1722, I

76 LABEAGA MENDIOLA, 5 (San Sebastián, 1991): 40.

77 LABEAGA MENDIOLA, 5 (San Sebastián, 1991): 50.

78 LABEAGA MENDIOLA, 4 (San Sebastián, 1988): 42.

79 LABEAGA MENDIOLA, 102 (Logroño, 1982): 128.

80 Son en total treinta actuaciones. Elaboración propia. La indicación "N" se refiere a un órgano de nueva planta, e "I" a una ampliación o reparación. 
- Viana (Navarra), iglesia de Santa María, 1722, I

- Toro (Zamora), colegiata de Santa María La Mayor, 1723, I

- Viana (Navarra), iglesia de San Pedro, 1726, N

- Mota del Cuervo (Cuenca), iglesia de San Miguel Arcángel, 1728 (junto con su hermano Francisco), I

- Veles, convento real de la orden de Santiago, 1729 (junto con su hermano Francisco), N

- Barahona (Soria), iglesia de San Miguel, 1730, N

- Hornillos de Eresma (Valladolid), iglesia de San Miguel Arcángel, 1731, N

- Santa María La Real de Nieva (Segovia), iglesia de Nuestra Señora de la Soterraña, 1731, I

- Puras (Valladolid), iglesia de la Asunción de Nuestra Señora, 1732 (hoy en Olmedo), N

- Villabuena (Álava), iglesia de San Andrés apóstol, 1734 (junto a su hermano Francisco), N

- Villeguillo (Segovia), iglesia de San Pedro apóstol, 1738, N

- Villada (Palencia), iglesia de Santa María (junto a su hermano Francisco), 1739, I

- Haro (La Rioja), iglesia de Santo Tomás, 1743, I $^{81}$.

\section{LOS ÓRGANOS DE FELIPE URARTE EN LA PROVINCIA DE VALLADOLID}

\section{-Pozaldez, Santa María}

Hay noticias de que Esteban de Arnedo hizo un instrumento en 1594 para la iglesia de Santa María, y que a su vez lo tomó como modelo para el de Rodilana. Posteriormente, intervinieron en tareas de afinación, Manuel Marín y Juan Bautista Juárez $^{82}$. Francisco Alemán lo repara en 1632 y años después un monje jerónimo de La Mejorada. En la visita de 1684 ordenan hacer uno nuevo, que es acabado por Antonio Ortega en $1690^{83}$. De nuevo, el Vicario General de la villa de Medina del Campo y canónigo vallisoletano, Toribio de Tovar, en nombre del obispo de Ávila, en la visita parroquial efectuada el 23 de mayo de 1716, ordena la ejecución de un nuevo órgano, tasado en la cantidad de 6.800 reales de vellón que se obtendrán del caudal de la fábrica. En mayo de 1716 ya están firmadas las "condiciones y obligaciones" con Felipe Urarte, "maestro en el arte" (calificativo equivalente en la actualidad a un profesional), el cura beneficiado, el licenciado Pedro de Matienza, cura de las parroquias unidas

81 Protocolos, 1722, Archivo General de Navarra, Viana, Juan de Ozcáriz: f. 62-65.

82 LAMA (1981): 306, y MARCOS VILLÁN y FRAILE GÓMEZ (2003): 165.

83 GARCÍA CHICO, XI (Barcelona, 1956): 196. de Santa María y San Boal; el mayordomo de la iglesia de Santa María, Antonio Diez Labajo, todos con la licencia del obispo abulense y reunidos ante el notario Alonso de To$\operatorname{var}^{84}$. El caudal se obtuvo de las rentas de la fábrica parroquial, tomadas el día 21 de febrero de 1716, y custodiadas bajo llave a la vez por el cura, el beneficiado mayor, y una tercera por el mayordomo de la iglesia ${ }^{85}$. Una vez acabado y revisado pericialmente, las cuentas de 1718 reflejan el importe gastado en él: 4.920 reales al organero Felipe Urarte, 180 reales a Francisco Ortega, "veedor" o perito, y 1.720 reales para clavazón y otras cosas necesarias ${ }^{86}$.

El órgano sufrirá mejoras y reparos en los años sucesivos, como las realizadas en $1720^{87}$; el dorado de la caja ejecutado por Francisco de Prado en 1740, por la cantidad de $2.265^{88}$, y en 1753 , lo arregla el organero de Valladolid Andrés Tamames.

En la actualidad se asienta en el lado del evangelio, con una caja de más de cuatro metros de alto y cinco castillos en la fachada ${ }^{89}$, y la siguiente disposición desde las modificaciones ejecutadas por Isidro Gill en 1785, añadiendo la Flauta travesera y la lengüetería, aparte de las últimas practicadas por Francisco Fernández, de Valladolid, y tasadas por el organista del convento de La Mejorada, fray José de San Telmo, en $1807^{90}$ :

$\begin{array}{ll}\text { Ventidosena } & \text { Ventidosena } \\ \text { Decinovena } & \text { Docena y Quincena } \\ \text { Quincena } & \text { Octava } \\ \text { Docena } & \text { Corneta } \\ \text { Octava } & \text { Flauta travesera } \\ \text { Flautado violón } & \text { Flautado de 13 } \\ \text { Flautado de 13 } & \text { Clarín claro } \\ \text { Clarín de bajos } & \text { Clarín de bajos } \\ \text { Bajoncillo } & \text { Trompeta magna } \\ \text { Trompeta real } & \text { Trompeta real }\end{array}$

84 Protocolos, 1718, AHPVa, Sig. 11775: f. 100-100 v.

85 Pozaldez, Parroquia de Santa María, Libro de Cuentas de la Iglesia Parroquial de Santa María (1700-1744), Visita de 23 de mayo de 1716, Archivo General Diocesano de Valladolid (AGDVa), Caja 5: s.f.

86 Pozaldez, Parroquia de Santa María, Libro de Cuentas de la Iglesia Parroquial de Santa María (1700-1744), Data 1718-1719, AGDVa, Caja 5: s.f.

87 Pozaldez, Santa María. Libro de Cuentas de la Iglesia Parroquial de Santa María (1700-1744), Data 1720-1721, AGDVa., Caja 5: s.f.

88 Pozaldez, Parroquia de Santa María. Caja 5, Libro de Cuentas de la Iglesia Parroquial de Santa María (1700-1744), Data 17381740, AGDVa: Caja 5: s.f., y MARCOS VILLÁN y FRAILE GÓMEZ (2003): 165.

89 LAMA, 1981: 306-308.

90 MARCOS VILLÁN y FRAILE GÓMEZ (2003): 165. 


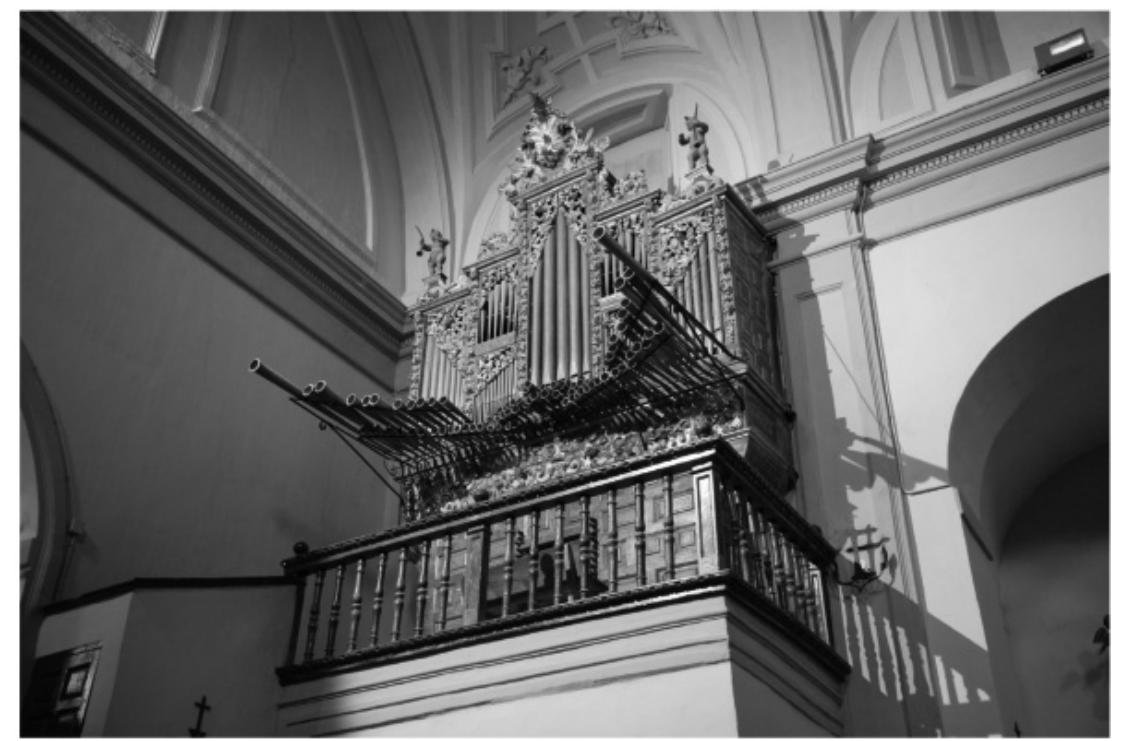

Figura 3. Fachada del órgano de la iglesia de San Boal de Pozaldez (José I. Palacios)

\section{-Olmedo. Convento Jerónimo de la Mejorada (ór- gano desaparecido)}

El Libro de Becerro que custodia la Biblioteca Histórica de la Universidad de Valladolid nos proporciona información sobre los órganos del cenobio. Las primeras noticias corresponden a 1516, acerca de dos positivos. En 1716 encarga el prior, fray Sebastián de Santa María, a Felipe Urarte, desmontar y ampliar el órgano existente, añadiendo unos registros y levantando una caja nueva con decoración ${ }^{91}$. Bajo el priorato de fray Juan de Cazares, el órgano de Urarte se embutió en el muro del coro, debajo de un arco, al mismo tiempo que la quiebra de las bóvedas de la iglesia aconsejó hacer un coro nuevo más largo y cerrado con balaustres de hierro (los anteriores eran de madera) $)^{92}$. El 1 de junio de 1772, los monjes jerónimos encargan a José Casas y Soler, por entonces organero para la misma orden en El Escorial, apear el órgano para corregir defectos ${ }^{93}$.

91 Libro Becerro del Monasterio de Nuestra Señora de la Mejorada, de La Orden de San Jerónimo, de la villa de Olmedo, 1760, Biblioteca Histórica de Santa Cruz, Valladolid (BHSC), Manuscrito MS258: f. 13 v., y LABEGA MENDIOLA, 5 (San Sebastián, 1991): 44.

92 Libro Becerro del Monasterio de Nuestra Señora de la Mejorada, de La Orden de San Jerónimo, de la villa de Olmedo, 1760, Biblioteca Histórica de Santa Cruz, Valladolid (BHSC), Manuscrito MS258: f. 15. Este manuscrito acaba en 1796 y ya no hay nuevas noticias sobre los órganos.

93 Libro Becerro del Monasterio de Nuestra Señora de la Mejorada, de La Orden de San Jerónimo, de la villa de Olmedo, 1760,

\section{-Moraleja de las Panaderas, San Boal (órgano desaparecido)}

En la iglesia de San Boal, existía un órgano remodelado por Felipe de Urarte en el mes de octubre de 1718, como así han recogido García Chico ${ }^{94}$, Lama ${ }^{95}$, Marcos Villán, Fraile Gómez ${ }^{96}$ y Jambou ${ }^{97}$. Aunque anteriormente había habido un órgano, los libros de cuentas parroquiales no dan referencia de este antiguo instrumento. La primera referencia dice así:

"Más seiscientos reales de vellón pagados a Phelipe Duarte, organero, de componer el órgano de dicha iglesia, como fue apearle, desaforrar el secreto, aforrarle de nuevo, dar reducción al teclado y ponerle algunos caños y quitar los fuelles"98.

Urarte tuvo que desmontar la tubería, desabollarla, eliminar las pérdidas de aire, arreglar los fuelles, renovar el teclado y sus reducciones, montar, y finalmente afinarle ${ }^{99}$.

Biblioteca Histórica de Santa Cruz, Valladolid (BHSC), Manuscrito MS258: f. 18, y CEA GALÁN (2009): vol. 3, 265.

94 GARCÍA CHICO (1964): vol. IV, 58.

95 LAMA (1981): 62 y 245.

96 MARCOS VILLÁN y FRAILE GÓMEZ (2003): 132.

97 JAMBOU (1988): vol. I, 56.

98 Moraleja de los Panaderos, Parroquia de San Boal, Libro de Fábrica (1678-1745), Data 1719, AGDVa, Caja 4: s.f.

99 Moraleja de las Panaderas, Parroquia de San Boal, Libro de Fábrica (1678-1745), Data 1719, AGDVa, Caja 4: s.f. 


\section{-Tordesillas}

Tordesillas desde el siglo XVI contó con seis parroquias, conventos, hospitales, cinco ermitas y palacios ${ }^{100}$. La construcción de los estos edificios y su ornato fue fruto de las actuaciones de donantes y mecenas, unas veces, y en otras ocasiones de los parroquianos, clérigos e hidalgos ${ }^{101}$. La más antigua de todas fue la iglesia de Santiago, concluida en 1564 y que daba cobijo a los hijosdalgo; después San Miguel, la más humilde; San Antolín, sede del consistorio; San Pedro, San Juan Bautista, como sede de los pecheros, y Santa María, siendo la principal y mayor, con la torre más opulenta y reloj municipal. Santa María defendió sus prerrogativas, frente a la otra iglesia más notable de la villa y rival, la de San Pedro, en el pleito de 1551. Todas poseyeron órgano con sus respectivos tañedores. Fueron varias generaciones que aprendían el oficio por transmisión directa de padres a hijos, y así durante varias décadas, como ocurre en San Juan, garantizando de este modo no solo el cuidado del instrumento, sino también un oficio remunerado sin excesos, por lo que tuvieron que compatibilizar este puesto con el de sacristán.

\section{Iglesia de Santa María}

La primera referencia de la iglesia de Santa María nos remonta a 1599. Gracias al libro de Visitas sabemos que se mandó cantar las misas, "sin que lo tome el choro ni el órgano, so pena de dos ducados por cada vez"102. Debía tratarse de un órgano perteneciente a la estética del quinientos y de tamaño mediano, que aún seguía usándose en años posteriores, como refleja el inventario de 1613, en el que da cuenta de un "órgano grande", junto a un facistol, y un salterio de pergamino de "Quintar regla" y un cuaderno con Credos ${ }^{103}$. Tres años después, el Visitador manda aderezarlo por el mal estado que presenta ${ }^{104}$.

El 28 de agosto de 1716 firman sendos protocolos ante el notario Manuel González Ollero, de una parte los licenciados, curas y beneficiados de la parroquial don Juan de Burgos, don Manuel González, don Manuel Maestro, don Francisco Zidre Rodríguez y don Joseph Ruiz de Témulos, y de la otra el organero Felipe de Urarte, con el fin de hacer un

100 FERNÁNDEZ TORRES (1982): 10-11 y 17, y CASTRO TOLEDO (1994): 155.

101 PARRADO DEL OLMO, 56 (Valladolid, 1990): 518-519. Caja 30: f. 36.

102 Tordesillas, Libro de Visitas Generales 1589-1656, AGDVa,

103 Tordesillas. Libro de Visitas Generales 1589-1656, AGDVa, Caja 30: f. 84 y 85.

104 Tordesillas. Libro de Visitas Generales 1589-1656, AGDVa, Caja 30: f. 112 v y 203 v. En 1640 se repite las normas para la procesión del Corpus que también se expone para la parroquia de San Pedro. nuevo órgano y la caja. El primer documento explicita que el órgano debía finalizarlo en marzo de 1717, y que al año volvería a "afinarle y registrarle" por si había algún defecto. El precio final asciende a 9.750 reales de vellón, además de recoger los despojos del órgano viejo. Las condiciones y materiales para levantar dicho instrumento "según arte", aparecen detalladas en el documento notarial, empezando por el secreto que sería de nogal, con las tapas, clavos de forja y registros de pino de Soria, que se abrirán "a mano" con los movimientos de hierro, menos el de la Trompeta real que es de roble, forrado con piel blanca. Además tendría un teclado de 42 notas, hecho de pino de Soria, con las "uñas" o naturales en hueso y las alzas o de palo santo; tres "teclas a los pies"; tres fuelles de abanico y marca "al modo moderno", con tarimas, palancas, caballete y conductos para llevar el órgano a los tubos (en la fachada son postajes de "hueso"), y 18 juegos, aunque en el contrato falta de reseñar el juego de lengua que debería ir en el costado izquierdo de la fachada y que debería ser para un Oboe partido de mano derecha, registro que aún pervive a las reforma de Rodríguez:

-Flautado de 13, con sus tablones, ubicados los tubos en los distintos castillos de la fachada (42 caños)

-Octava clara, una parte asentada en los cubos laterales de fachada (42 caños)

-Docena clara abierta (42 caños)

-Quincena (42 caños)

-Diez y novena (42 caños)

-Veintidosena con tres tubos por notas con las reiteraciones "al estilo moderno" (126 caños)

-Címbala con sus "aumentaciones" de tres hileras, también al "estilo moderno" (126 caños)

-Tapadillo (42 caños)

-Nasardo en quincena (42 caños)

-Corneta real, de siete hileras (147 caños) y Corneta en eco de seis filas (126 caños), ambas en secretillos independientes con sus tablones

-Clarín, con su tablón y "barrilla", en el centro de la fachada, "a modo de artillería" (21 caños)

-Bajoncillo, en el semicírculo izquierdo del frontis (21 caños)

-Chirimía de mano izquierda en el cubo derecho (21 caños)

-Dulzaina con su zoquetería por encima del organista (42 caños)

-Trompeta real entera (42 caños)

-Trompeta magna, de tiples, en un costado (21 caños)

-Tambor con dos tubos que cantan en de Lasolre y Timbal en Alamire. 
La escritura de obligación de la caja es signada por los mismos clérigos precitados, el maestro arquitecto de Simancas, Gabriel Alonso, y el entallador vallisoletano, Francisco de la Bastida. Los artistas se comprometen a instalar el órgano en el coro alto -sin ser de su responsabilidad el anclaje en el muro-, en el mismo sitio en el que estaba el órgano viejo; es decir, encima del arco de la puerta lateral norte, frente a la puerta principal, conforme a las trazas que diseñaron, justo en el coro alto del evangelio, como era costumbre en Castilla. La caja tendrá más de $5 \mathrm{~m}$ y medio de alta y casi $2 \mathrm{~m}$ de ancha, con cinco castillos al frente, tres de los cuales en forma de cubo, siendo el central el mayor (de casi $3 \mathrm{~m}$ ), y los otros dos en las esquinas para unir el frontis con cada lateral. La caja tiene un sentido decreciente de abajo a arriba, ensanchándose a la altura de los secretos, y complicando su decoración en el mismo orden. Conjuga un rico dorado con el color azul del lapislázuli. Las cláusulas de reconocimiento y pago son similares a otros contratos: el reconocimiento lo efectuarán dos maestros y en el pago en tres fracciones, una primera de 1.000 reales, al principio, para poder comprar madera y materiales; otra idéntica al medio, y los 500 restantes al acabar, lo que hace un total de 2.500 reales $^{105}$. La obra está finalizada en enero de 1717, unos meses antes de lo pactado para ajustar toda la maquinaria antes de iniciarse el proceso de peritación, y será reconocida por Diego de Orio Tejada, natural de Escara, arzobispado de Burgos, y residente por entonces en Valladolid, ocupado en la finalización del órgano para el convento de San Benito el Real. La declaración firmada ante notario, el 22 de octubre de 1718 , detalla el examen interior y exterior del órgano, que va desde su ubicación "en la parte más a propósito y conveniente para el servicio y adorno de la Iglesia", hasta la revisión de las condiciones contractuales. En el informe declara que está bien ejecutado en "lo substancial", alabando algunas mejoras, como fueron el colocar una quincena doble en la mano derecha que no estaba contratada y el forro con baldeses de los fuelles en la parte externa. También detecta el escaso recorrido de la tapa del arca de la Corneta de ecos, que debía ser de "cinco cuartos en alto" y que debería rearmonizar y afinar de nuevo la corneta, quitándolo algo de "cuerpo" para que "no se confundan las voces" 106 .

En un escrito fechado en 1718 y dirigido al obispo de la diócesis, Joseph de Talavera, Urarte solicita cobrar 1.200 reales que aún le debía la fábrica del importe total, según lo estipulado contractualmente. El despacho es remitido a los curas de la parroquia el 10 de noviembre instándoles a que realicen el pago en el plazo de ocho días so pena de excomunión. En otro comunicado, los clérigos trasladan al obispado que carecían de fondos suficientes, pidiendo dilatar la entrega medio año. El prelado Talavera autoriza, el 20 de junio de 1720 , a vender grano para poder satisfacer esta deuda ${ }^{107}$.

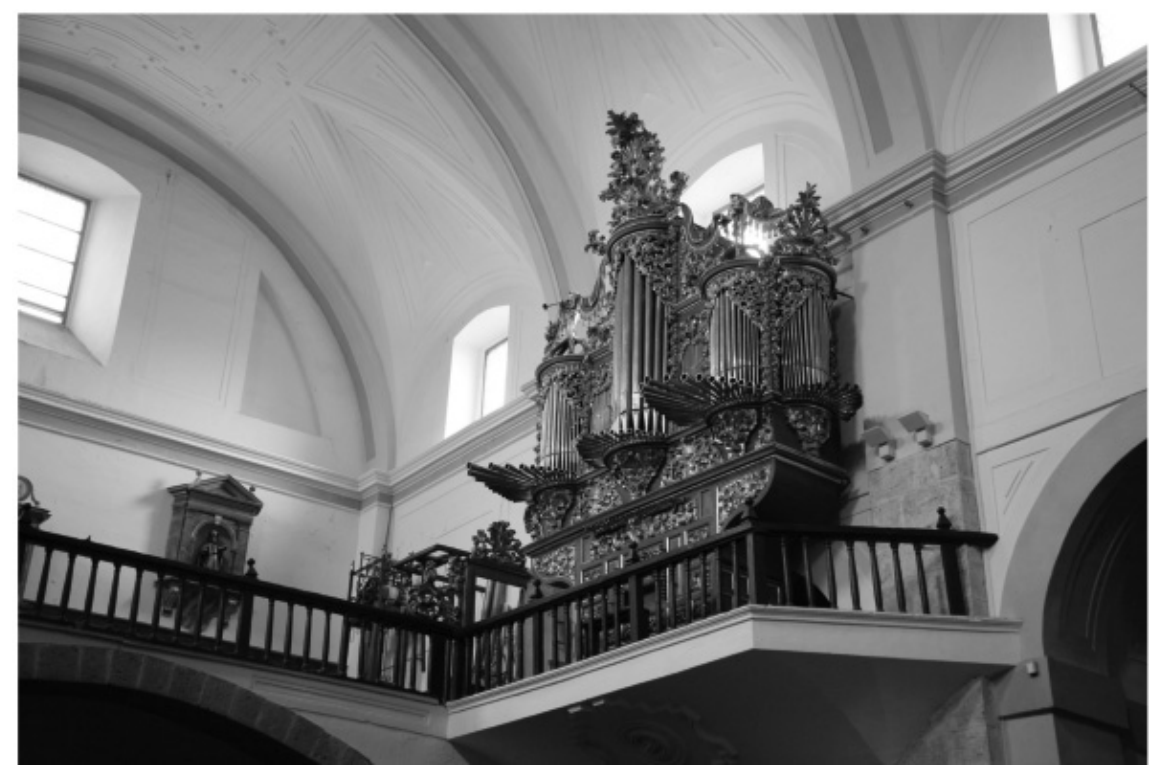

Figura 4. Vista del órgano de Santa María de Tordesillas (José I. Palacios) 56, AGDVa, Caja 20: s.f. 
Transcurrieron varios años hasta que se realiza una intervención de cierta envergadura en el órgano, tasada en 900 reales con el organero vallisoletano Joseph de Ballesteros. La situación era caótica al estar el instrumento en mal funcionamiento, sucio y con varios juegos y tubos mudos. En septiembre de 1756 el mayordomo describe el proceso de desmonte, reparación de los fuelles, registros, ("trompetas y enflautados"), soldar los tubos, afinarle y "reafinarle", hasta dejarle "corriente y a satisfacción del organista". Al mismo tiempo, gracias a la generosidad del parroquiano don Tomás González Blanco, agente de negocios, y residente en Madrid, se ajustó con el maestro de la corte José de Bustamante y su oficial Antonio dorar la talla de la caja y colorear de azul los "llanos" y frisos, imitando el lapislázuri, por la cantidad de 4.500 reales de vellón, siendo únicamente por cuenta de la fábrica cubrir los gastos de su hospedaje en Tordesillas ${ }^{108}$. En primer lugar, fue necesario montar un andamio desde el suelo a las bóvedas, que ejecutó Francisco Aller por 100 reales, para facilitar los trabajos del dorador. La obra por concluyó el 1 de diciembre de ese mismo año de 1756 , junto a los reparos y afinación del organero, dándose por buena. Los gastos de la fábrica parroquial quedaron reflejados en estas partidas:

-Por buscar en Rioseco retal para la cola, refresco y alquiler de un burro para montar el andamio, 36 reales

-De un "tinajón" para echar la cola, de "seis costales de yeso" para dar la primera mano a la caja y tapar los agujeros en la pared en donde se asentó el andamio, 18 reales

- A Jacinto de la Lastra por hacer dos trompetas de madera para los ángeles de la corona del órgano, 8 reales

-Por 48 cargas de leña para "coser" la cola y otros ingredientes del dorado, 160 reales

-Hospedaje del maestro dorador y su oficial durante tres meses, 180 reales

-Vasijas de vidrio y barro, 48 reales

-A Joseph Bustamante, 300 reales de vellón, de "agasajo y guantes", por haber dejado la obra "al parecer con toda perfección por razón del más gasto que hizo"

-A su oficial Antonio, 40 reales de "agasajo"

-A la criada que les asistió, 40 reales

-De una docena de "lias y media de sogas carroceras" que se gastaron en "afianzar" los andamios, tapar los agujeros, limpiar las paredes y llevar un órgano pequeño mientras se ejecutaba la obra, 60 reales

-Regalo de vino al dorador, 32 reales

-Al organero, 30 reales del día que vino hacer un registro y ajustarle

108 PARRADO del OLMO, 56 (Valladolid, 1990): 521.
-Del oficial del organero, Corcobado, de agasajo una vez concluido, 20 reales y otros 20 al organero, que pagó Joseph Miguel, mayordomo de la fábrica

-30 reales de hacer una "trampita" para cerrar el teclado, de unas bisagras para afianzar la tabla que está sobre las trompetas

-48 reales de carbón que tenía la carbonera de la iglesia y que se dio a los doradores para calentar las colas y los colores $^{109}$.

El precio total del dorado y dejar el instrumento a punto y en perfecto estado para ser usado, al final ascendió a 6.570 reales de vellón, pagados primeramente al dorador 4.500 reales, que don Gabriel en Madrid obtuvo 1.000 reales del Comisario General de los Reinos por la falta de fondos de la fábrica de la parroquia, y que se libraron al canónigo de Valladolid Pedro Aspiazo, más 300 reales de las limosnas de los pobres que dio la iglesia de Santiago de Valladolid, y que se entregó como gratificación al dorador. Las dos últimas cuentas de las partidas las pagó de su bolsillo el organista de la iglesia Joseph Miguel García. Aun así había un déficit de 672 reales, que subsanó don Gabriel Hermenegildo Arhueso en calidad de limosna ${ }^{110}$.

El organista Antonio Campos reconoce el instrumento el 4 de octubre de 1791, que aún conservaba la disposición de Urarte. En 1830 estaba inservible, y el organero del obispado de Segovia, Joaquín Bernis, es el encargado de realizar los reparos ${ }^{111}$. A esta intervención hay que sumar la de Juan Ballesteros treinta y tres años después, que costó 90 reales $^{112}$. Pero será en 1865 cuando se produzcan la intervención más profunda y que alterará sin grandes modificaciones sustanciales el instrumento, a cargo de Marcial Rodríguez, por el precio de 6.300 reales ${ }^{113}$. En ella, tal y como llegó hasta nosotros antes de su reciente restauración, amplia el secreto por los bajos cuatro notas y nueve en los tiples, quedando un

109 Tordesillas, Parroquia de Santa María, Libro de Cuentas de Fábrica 1690-1763, Data 1756-57, AGDVa, Caja 26: s.f.

110 Tordesillas, Parroquia de Santa María, Libro de Cuentas de Fábrica 1690-1763, Data 1756-57, AGDVa, Caja 26: s.f. En septiembre de 1757 inician la obra de la verja de hierro del coro bajo que se había levantado en 1689 y que costó $1.583,5$ reales, a cargo de Francisco Ruiz, al mismo tiempo que regala un óleo de san Antonio Thomás González Blanco que adquirió en una casa de Madrid, de seis varas y media de largo y tres y media de alto. Véase también Data 1693, s.f. Asimismo, es reseñable la compra de un reloj con sonería para la sacristía, adquirido en Londres a Daniel Torín, por el precio de 2.200 reales.

111 Tordesillas, Parroquia de Santa María, Legajo órgano, $\mathrm{n}^{\circ}$ 53, AGDVa, Caja 20: s.f.

112 Tordesillas, Parroquia de Santa María, Libro de Cuentas de Fábrica 1845-1879, Data 1853, AGDVa, Caja 28: f. 18 v.

113 Tordesillas, Parroquia de Santa María, Legajo órgano, AGDVa, Caja 20: s.f. 
teclado de 54 notas. Asimismo, desmontaría toda la tubería y reconocería los tubos para que los que resultasen inservibles, según la tesitura, se pudieran emplear en la ampliación o se harían de nueva factura. Se haría un nuevo Bajoncillo más suave y sonoro, la Dulzaina pasa a llamarse Orlo, la rodillera derecha acciona al mismo tiempo el Clarín junto a la Corneta, y se suprime la Címbala por un Clarinete. A los dos fuelles, debajo del arco, se les dotaría de dos más pequeños en un lateral, alimentarlos por manivelas ${ }^{114}$. El resultado final de Rodríguez era este:

$\begin{array}{ll}\text { Flautado } & \text { Flautado } \\ \text { Octava } & \text { Octava } \\ \text { Docena } & \text { Docena }\end{array}$

$\begin{array}{ll}\text { Quincena } & \text { Quincena } \\ \text { Decinovena } & \text { Flautín } \\ \text { Ventidosena } & \text { Ventidosena } \\ \text { Lleno } & \text { Lleno } \\ \text { Tapado } & \text { Tapadillo } \\ \text { Nasardo } & \text { Flauta } \\ \text { Corneta } & \\ \text { Trompeta real } & \text { Trompeta real } \\ \text { Chirimía } & \text { Oboe } \\ \text { Orlo } & \text { Orlo } \\ \text { Bajoncillo } & \text { Clarinete } \\ & \text { Corneta-Clarín (rodillera) } \\ & \end{array}$

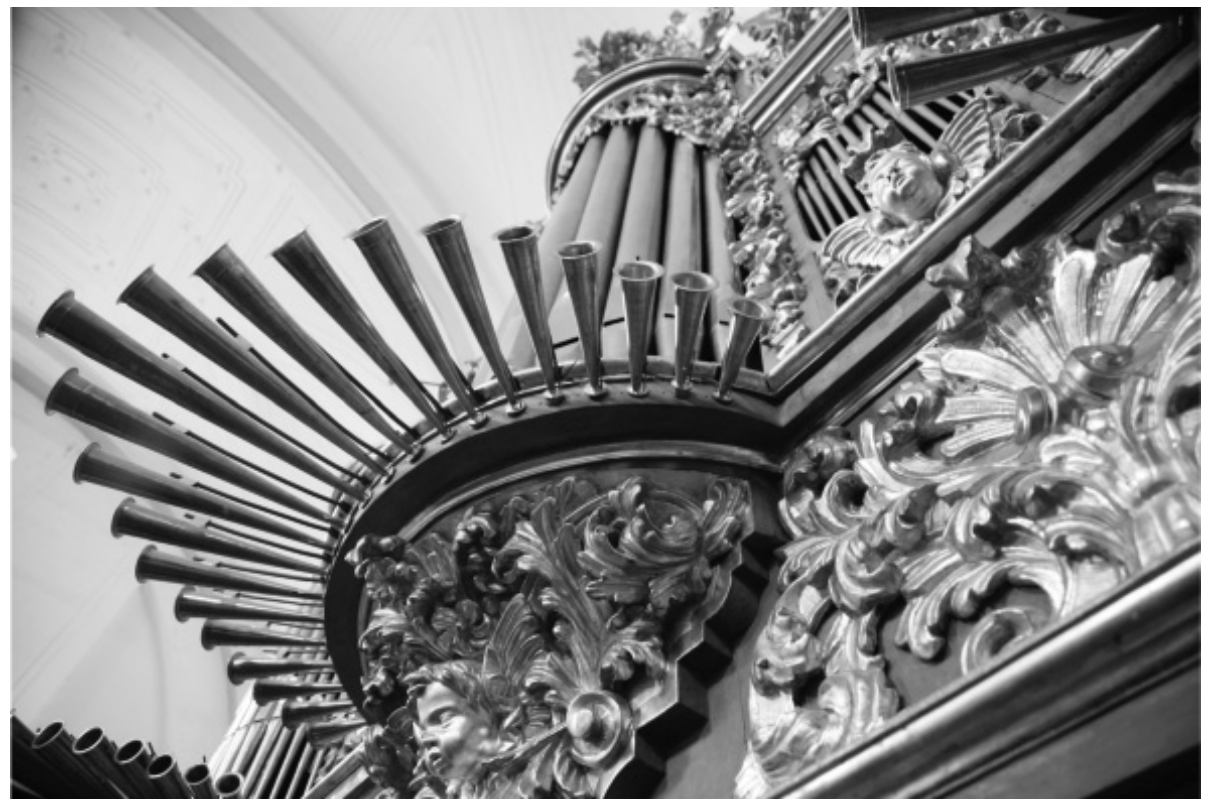

Figura 5. Detalle de la lengüetería de fachada, Santa María de Tordesillas (José I. Palacios)
El órgano fue desmontado hacia 1972 hasta que Fermín Trueba y Jesús Ángel, en 1984, remontan la tubería y lo ponen en funcionamiento. Recientemente ha sido restaurado por los talleres de Joaquín Lois Cabello en 2011, siendo inaugurado por Juan Pedrero Encabo en julio de 2011, recobrando su aspecto original con esta disposición, tanto la espectacular caja, llena de filigranas barroquizantes, de las más reseñables en el mobiliario organístico en Castilla y León, con tres caras cantantes, y esta disposición sonora:

114 Tordesillas, Parroquia de Santa María, Legajo órgano, AGDVa, Caja 20: s.f.

$\begin{array}{ll}\text { Flautado de } 13 & \text { Flautado de } 13 \\ \text { Octava } & \text { Octava } \\ \text { Docena } & \text { Docena } \\ \text { Tapadillo } & \text { Tapadillo } \\ \text { Quincena } & \text { Quincena } \\ \text { Decinovena } & \text { Decinovena } \\ \text { Ventidosena } & \text { Ventidosena } \\ \text { Trompeta real } & \text { Trompeta magna } \\ \text { Bajoncillo (rodillera) } & \text { Clarón (rodillera) } \\ \text { Chirimía } & \text { Oboe } \\ \text { Dulzaina } & \text { Dulzaina } \\ \text { Tambor y Timbal } & \text { Corneta real y Ecos. }\end{array}$


Según Lois, la tubería tiene una aleación de $50 \%$ de estaño y plomo, sin dientes en el Flautado, con una armonización de forma circular, un diapasón de $\mathrm{A}=412 \mathrm{~Hz}$ a $22^{\circ} \mathrm{C}$, un temperamento de $1 / 4$ de coma, y la siguiente composición en los llenos:

$\begin{array}{clc}\text { Lleno } & \text { C1 } & 22,26,29 \\ & \text { C\#3 } & 15,19,22 \\ \text { F\#3 } & 8,12,15 & \\ \text { A4 } & 8,12,15 & \\ \text { Címbala: } & \text { C1 } & 26,29,33 \\ \text { C\#3 } & 19,22,26 \\ \text { F\#3 } & 12,15,19 \\ \text { A4 } & 12,15,19^{115} .\end{array}$

Siguiendo las especificaciones del contrato de Urarte llama la atención la ausencia de la Trompeta real interior de tiples que él suplió por un Oboe, y la falta de la doble quincena que tanto ensalzó Orio en el proceso de reconocimiento. Por último, en estas últimas reparaciones se han desplazado de su ubicación original la Chirimía, la Trompeta magna y el Oboe.

\section{San Pedro}

Los primeros datos del órgano de la parroquia de San Pedro de Tordesillas se remontan a 1571, cuando el Visitador del obispado mandó "aderezar el horgano" con todo lo necesario en el plazo de medio año ${ }^{116}$. Con toda probabilidad se pudo montar hacia 1565 (el inventario redactado el 6 de noviembre de 1555 no da constancia de él, pero si de un salterio nuevo, tres pasionarios, dos breviarios palentinos y un libro de difuntos cantado con los salmos procesionales) ${ }^{117}$. De nuevo, en 1670, se pretende hacer un nuevo órgano por 500 reales $^{118}$, al tener necesidad de un "reparo considerable" 119 . La reforma más profunda llega de la mano de Manuel Benito Gómez, el 2 de julio de 1714, con el refrendo del obispo, don Andrés de Orueta Barasorda ${ }^{120}$. Las obras se centran en levantar una caja nueva y en añadir varios registros que aparece detallados en la memoria previa ${ }^{121}$, firmada ante el escribano público Francisco del Castillo: inclusión en la fachada del juego de Clarín de mano derecha de 21 notas,

115 LOIS (2011): 20, 25-26 y 31.

116 Tordesillas, Parroquia de San Pedro, Libro de Visitas, 1555, AGDVa, Caja 19: f. 38 v.

117 Tordesillas, Parroquia de San Pedro, Libro de Visitas, 1555, AGDVa, Caja 19: f. 6 v.

118 Tordesillas, Parroquia de San Pedro, Libro de Visitas, 1555, AGDVa, Caja 19: f. 185.

119 ARA GIL y PARRADO del OLMO (1980) tomo XI, 224

120 CASTRO ALONSO (1904): 297-299.

121 Protocolos, 1714, AHPVa, Sig. 5297: f. 425-425 v. como está en el del convento de Santa Clara de esta villa, una Dulzaina de ambas manos de 42 notas, más la Trompeta real en el interior, y añadir unas filas al Lleno y a la Címba$1 a^{122}$. El precio total a entregar al organero suma 6.400 reales de vellón, desglosado en estas partidas: 600 reales el día de la firma del contrato, 400 reales al mes, 3.000 reales una vez esté acabado y dado por buena, y los 2.400 reales restantes cuatro meses después ${ }^{123}$.

El junio de 1715 el órgano está acabado y peritado por el maestro vallisoletano Gregorio González Roldán y estrenado por Francisco Rodríguez de Albituturría ${ }^{124}$.

Siete años después, el 4 de septiembre de 1722, el cabildo parroquial acuerda con el organero Felipe Urarte unas mejoras en el órgano. Manuel González, notario apostólico, redacta el 24 de septiembre de 1722, un escrito solicitando al obispado el oportuno permiso, y da cuenta del estado de conservación del órgano a partir de varios informes, en los que subrayaba la falta de algún juego y las condiciones que presentaba. Los arreglos valdrán 2.300 reales ${ }^{125}$.

En las obligaciones de Urarte, describe un instrumento de 42 teclas, que presenta algunas anomalías en las reiteraciones de la Címbala, la falta de igualdad en el Clarín, la ausencia de tubos en la Corneta y Dulzaina, y las numerosas fugas de aire en la fuellería. Al mismo tiempo, el nuevo proyecto suprime la Trompeta real de mano derecha por una Trompeta magna y coloca un registro de Tapadillo, como síntoma de que los juegos solistas partidos tienen una gran

122 Protocolos, 1714, AHPVa, Sig. 5297: f. 427-428.

123 Protocolos, 1714, AHPVa, Sig. 5297: f. 428 v., y f. 539-541 v. Los curas de la parroquia, encabezados por don Francisco Reinalitos, preste más antiguo de la iglesia de San Pedro, junto a Alaejos y el mayordomo Casado, toman a censo, primero con la autorización del provisor del obispado, don Andrés de Orbe y Lareategui, de 10 de septiembre de 1714, ejecutada ante Miguel Ortiz Gil, notario de Asiento de la Audiencia Eclesiástica, y después, el 21 de septiembre, por medio de escritura pública ante Redondo del Castillo, la cantidad de 4.400 reales de vellón al 3\% del convento Real de Comendadoras de San Juan Bautista de Jerusalén, de los 10.000 que guarda el archivo conventual de las dotes de doña Angelina de Nieva, religiosa profesa y de su priora doña Isabel Delgado. En las condiciones aceptan pagar al convento 132 reales en dos plazos, el primero en la pascua de Navidad de ese año y el siguiente para la fiesta de San Juan del siguiente. La parroquia avala con los bienes detallados en la escritura, y entre otras condiciones figura el que los beneficiados de la iglesia otorgarán escritura de reconociendo del censo de diez en diez años

124 Protocolos, 1715, AHPVa, Sig. 5298: f. 255-256 v.

125 Tordesillas, Parroquia de San Pedro, Libro de Cuentas de Fábrica 1703-1749, 1722, Legajo cosido, AGDVa, Caja 16: s.f. Se recogen las autorizaciones y testimonios de Manuel de Gordo, cura de San Miguel; Manuel de Barzenilla, cura del Hospital de Mater Dei; Antonio Rodríguez Carrillo, cura de San Antolín, y Manuel Martín Carrillo, realizadas entre el 28 y el 30 de septiembre. El 17 de octubre el obispo diocesano, fray Joseph de Talavera, concede la oportuna licencia para realización de obras y reparos en el órgano de la iglesia de San Pedro. 
importancia en la paleta sonora de este maestro. Por último, revisa la fuellería ${ }^{126}$.

El preste de la parroquial acepta las condiciones del maestro y las formas de pago. En la primera partida entregan 1.150 reales para el organero, 260 reales a Manuel Calderón, dorador y estafador, más 540 reales que pagó de limosna el cura don Joseph de Alaejos; 16 reales del andamio y 27 reales y medio de componer los fuelles ${ }^{127}$. En las cuentas bianuales posteriores aparece una segunda partida a Urarte de 600 reales, además de 400 reales, en concepto de "una porción de estaño" que trajo su hermano Francisco ${ }^{128}$. El 30 de mayo de 1724 se completó los pagos con 500 reales más ${ }^{129}$.
En 1736 el instrumento está descompuesto y fue reparado al año siguiente por fray Cipriano Payueta, por el precio de 4.240 reales $^{130}$. A ésta le suceden las intervenciones de Valentín Ballesteros en $1792^{131}$; Rafael Moreno, vecino de Tudela de Duero y constructor de pianos y órganos, en junio de $1861^{132}$; en 1864 Marcial Rodríguez, hasta su restauración en 1989, a cargo de Joaquín Lois ${ }^{133}$. Descansa en el coro lateral de la epístola, a los pies de la iglesia. Va partido, con 45 notas y tiene estos registros:

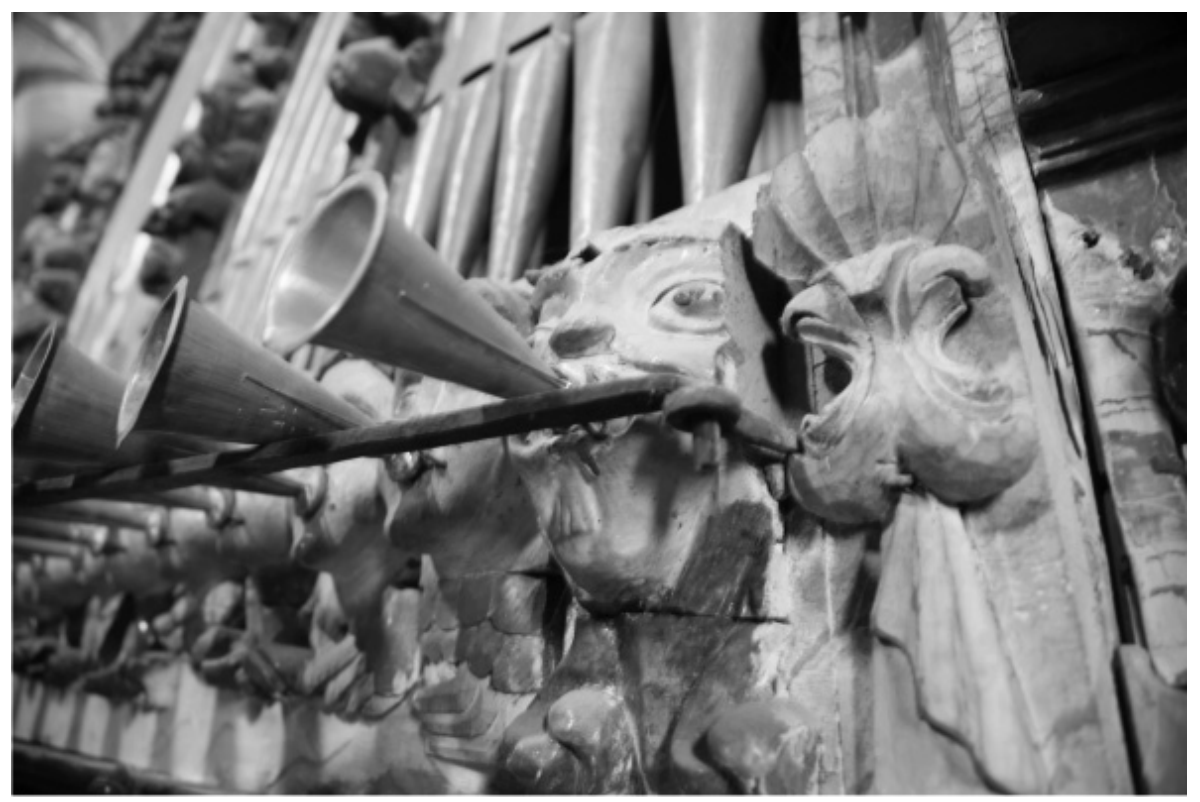

Figura 6. Detalle de los mascarones de la lengüetería del órgano de la iglesia de San Pedro de Tordesillas (José I. Palacios)

126 Tordesillas, Parroquia de San Pedro, Legajo cosido del órgano, AGDVa, Caja 16: s.f.

127 Tordesillas, Parroquia de San Pedro, Libro de Cuentas de Fábrica 1703-1749, Data 1721-1722, AGDVa, Caja 16: s.f.

128 Tordesillas, Parroquia de San Pedro, Libro de Cuentas de Fábrica 1703-1749, Data 1723-1724, AGDVa, Caja 16: s.f.

129 Tordesillas, Parroquia de San Pedro, Libro de Cuentas de Fábrica 1703-1749, Data 1723-1724, AGDVa, Caja 16: s.f.
130 Tordesillas, Parroquia de San Pedro, Libro de Cuentas de Fábrica 1703-1749, Data 1723-1724, AGDVa, Caja 16: s.f.

131 Tordesillas, Parroquia de San Pedro, Libro de Cuentas de Fábrica 1749-1837, Data 1785-1790 y 1791-1792, AGDVa, Caja 17: s.f.

132 Tordesillas, Parroquia de San Pedro, Libro de Cuentas de Fábrica 1855-1878, 1861, Hoja suelta con las Condiciones para el arreglo de los órganos de San Pedro y San Antolín, AGDVa, Caja 18: s.f. Se trata de un claro ejemplo de mantenedor local de órganos, que a su vez construye pianos.

133 http://www.proyectoclarin.com/001 Proyecto Clarin.php? idioma=ESP (última consulta 5 noviembre de 2011). 


$\begin{array}{ll}\text { Flautado } 13 & \text { Flautado } 13 \\ \text { Octava } & \text { Octava } \\ \text { Docena } & \text { Docena } \\ \text { Quincena } & \text { Quincena } \\ \text { Decionovena } & \text { Decinovena } \\ \text { Lleno } & \text { Lleno } \\ \text { Címbala } & \text { Címbala } \\ \text { Trompeta real } & \text { Trompeta real } \\ & \text { Clarín }^{134} .\end{array}$

Iglesia de Santiago (órgano desaparecido)

A principios del siglo XVIII la iglesia sufre serios problemas estructurales en la fábrica del arco formero en el que descansa el coro alto. Antonio Maestro, oficial carpintero, y Antonio García Zamorilla, maestro de cantería, ambos vecinos de Tordesillas, informan, a petición de cura, si se debía mudar la ubicación del órgano del coro alto al bajo, o bien rehacer aquél por la amenaza de ruina ${ }^{135}$. Por estos años encarga la parroquia a Felipe Urarte realizar un órgano nuevo, como recoge el protocolo de Santa María, que le servirá de modelo para aquella, aunque algo menor, con dos juegos menos y sin una fila en la Corneta de ecos ${ }^{136}$. Al respecto, también declaró en su dote matrimonial de 1722, que el párroco de esta iglesia, don Benito García, le debía 1.000 reales de vellón ${ }^{137}$.

\section{Convento de Santo Tomás (órgano desaparecido)}

No se conserva y solo tenemos constancia de que tuvo un órgano hecho por Felipe Urarte, en 1721, por el débito del prior del convento, fray Mateo Galán, de 1.000 reales de vellón ${ }^{138}$.

\section{-Medina del Campo \\ Parroquia de San Miguel.}

Aunque no hay un documento escrito que lo ratifique, suponemos con toda seguridad, que Urarte fue el que ejecutó la restauración del órgano en 1722. Los libros de cuentas relatan que se debe a un organero 120 reales de un total de 500 reales en que se ajustaron las reformas, para lo cual el mayordomo vendió varias fanegas de trigo, junto a las limosnas de devotos y beneficiados de la iglesia ${ }^{139}$.

134 LAMA (1981): 350.

135 Tordesillas, Parroquia de Santiago, Hoja suelta, AGDVa, Caja 37: s.f.

136 Protocolos, 1716, AHPVa, Sig. 5446: f. 121.

137 LABEAGA MENDIOLA, 5 (San Sebastián, 1991): 43.

138 PALACIOS SANZ (2008): vol. I, 85.

139 Medina del Campo, Parroquia de San Miguel Arcángel, Libro de Cuentas de Fábrica (1716-1783), Data 1722, AGDVa, Caja 51: s.f.; Medina del Campo, Parroquia de San Miguel Arcángel, Libro

\section{Convento de San Andrés (órgano desaparecido)}

Es más que plausible que las relaciones de amistad con la orden de los dominicos, plasmadas anteriormente en el órgano Santo Tomás de Tordesillas, pudieron haber traído a Urarte hasta Medina del Campo ${ }^{140}$. Tan solo conocemos la deuda contraída de la comunidad con él de 1.000 reales en $1722^{141}$.

\section{-Simancas}

Parroquia de el Salvador (órgano desaparecido)

La Fábrica parroquial mantuvo un órgano construido por fray Gaspar de Vitoria, en Medina de Rioseco, en $1645^{142}$. El órgano de la parroquia del Salvador recibió un último aderezo, en 1715, por la cuantía de 132 reales, siendo el organista del mismo Juan de Aranceta ${ }^{143}$. Cuatro años más tarde, en 1719, las cuentas parroquiales registran el gasto de 2.153 reales, entregados por don Andrés Díaz Campos, para el órgano nuevo de la iglesia, que había sido comprometido con Felipe Urarte el 4 de enero de ese mismo año ${ }^{144}$. El órgano viejo había quedado deshecho y destruido casi por completo, por lo que se levantó ex novo la tubería y cuyo coste fue de 121 reales $^{145}$. En 1720, se emplean 300 reales más, y, en 1722, 191 reales y tres maravedíes, de los cuales 97 reales fueron para Urarte, con lo que se le acabó de pagar, incluido los gastos de su mantenimiento y operarios, lo que hacen un total de 8.854 reales de vellón ${ }^{146}$. La caja fue encargada al ensamblador Gabriel Alonso, vecino de Tordesillas y autor de la de Santa María de esta localidad, al que abonaron 1.590 reales, de los cuales 30 reales fueron por la traza de la caja, 1.300 reales del coste, y 60 reales del trabajo de asentarla ${ }^{147}$.

de Cuentas de Fábrica (1694-1758), AGDVa, Caja 71: s.f., y LAMA (1995d): 347. En un pie de fotografía apunta que Urarte lo construyó en 1724 .

140 Libro de Becerro e Índice de las posesiones que tenía el extinguido convento de S. Andrés de la Orden de Santo Domingo, 1731, Archivo del Convento de San Andrés, Medina del Campo: f. 15 v., 51 v. y 320 v.-333.

141 LABEGA MENDIOLA, 5 (San Sebastián, 1991): 43. III, 2375 .

142 LAMA, (1981): 335 y REINOSO ROBLEDO (1991): vol.

143 Simancas, Parroquia El Salvador, Libro de Cuenta y Fábrica (1715-1725), Data 1715, AGDVa, Caja n ${ }^{\circ}$ 4: f. 14 v. y 18.

144 Simancas, Parroquia El Salvador, Libro de Cuenta y Fábrica (1724-1744), AGDVa, Caja no 5: f. 12. Juan de Aranzeta siguió durante este primer tercio de principios del siglo XVIII en el desempeño de sus funciones, tanto de sacristán como de organista, con el sueldo de 660 reales.

145 Simancas, Parroquia El Salvador, Libro de Cuenta y Fábrica (1715-1725), AGDVa, Caja nº 4: f. 163 y 168.

146 Simancas, Parroquia El Salvador, Libro de Cuenta y Fábrica (1715-1725), Data 1715, AGDVa, Caja no 4: f. 188 v y 260 v-261.

147 MARTÍN GONZÁLEZ (1973): 102 y 108. 


\section{-Hornillos de Eresma (órgano desaparecido)}

La única referencia documental es de 1731 , momento en el que el visitador manda levantar un órgano por "hallarse esta Iglesia con bastante caudal" 148 . En 1860, José Otorel asienta un nuevo instrumento muy parecido al de Piñel de Abajo y con 15 medios juegos, desapareciendo todo rastro del anterior ${ }^{149}$.

\section{de Olmedo) \\ -Puras (actualmente en la iglesia de Santa María}

Durante la visita pastoral, celebrada el 15 de marzo de 1731, se comprobó el "exceso de caudal" que presentaban las cuentas parroquiales y la necesidad de un nuevo instrumento digno y decente, ya que "el órgano que tiene es viejo y muy malo", y la iglesia precisaba de un "mayor ornato". De este modo, se concede licencia para que se fabriquen un órgano "decente" y dos retablos ${ }^{150}$. El Provisor de Ávila, el licenciado Joseph Guerrero, canónigo de la catedral y Vicario General de la diócesis, expide las oportunas licencias y autos. Entonces, se rubricaron las condiciones ante el notario Juan Jiménez González, el 17 de octubre de ese mismo año ${ }^{151}$. Juan Ximénez es el encargado de seleccionar la propuesta redactada por Felipe Urarte, hombre de "toda conciencia", ya conocido en el obispado de Ávila por los trabajos efectuados en Santa María de Nieva, en el convento de la Mejorada, Tordesillas, y el que peritó para San Ildefonso de la Granja de Valasín, y que venía avalado por Juan Rico y la referida comunidad jerónima de La Mejorada ${ }^{152}$.

148 Hornillos, Parroquia de San Miguel Arcángel, Libro de Fábrica (1697-1754), Data 1731, AGDVa: f. 189.

149 LAMA (1981): 157-159. Hace ya unos años fue desmontado y llevado a los almacenes de la catedral de Valladolid. Nunca se hizo nada con él. Recientemente, la Fundación del Patrimonio de Castilla y León, en su Memoria anual correspondiente al año 2006, apunta que comenzaría su restauración, y su futura instalación en la iglesia parroquial de San Martín de Valladolid, sin que todavía se haya hecho realidad.

150 Puras, Parroquia Ascensión de Nuestra Señora. Libro de Fábrica (1709-1796), Decretos de Visita, AGDVa: f. 69. $88 / 6 / 1^{\circ}$ : s.f.

151 Pleitos, Archivo Diocesano de Ávila (ADAv), Caja 1031,

152 Pleitos, (ADAv), Caja 1031, Documento n ${ }^{\circ}$. 12, s.f.

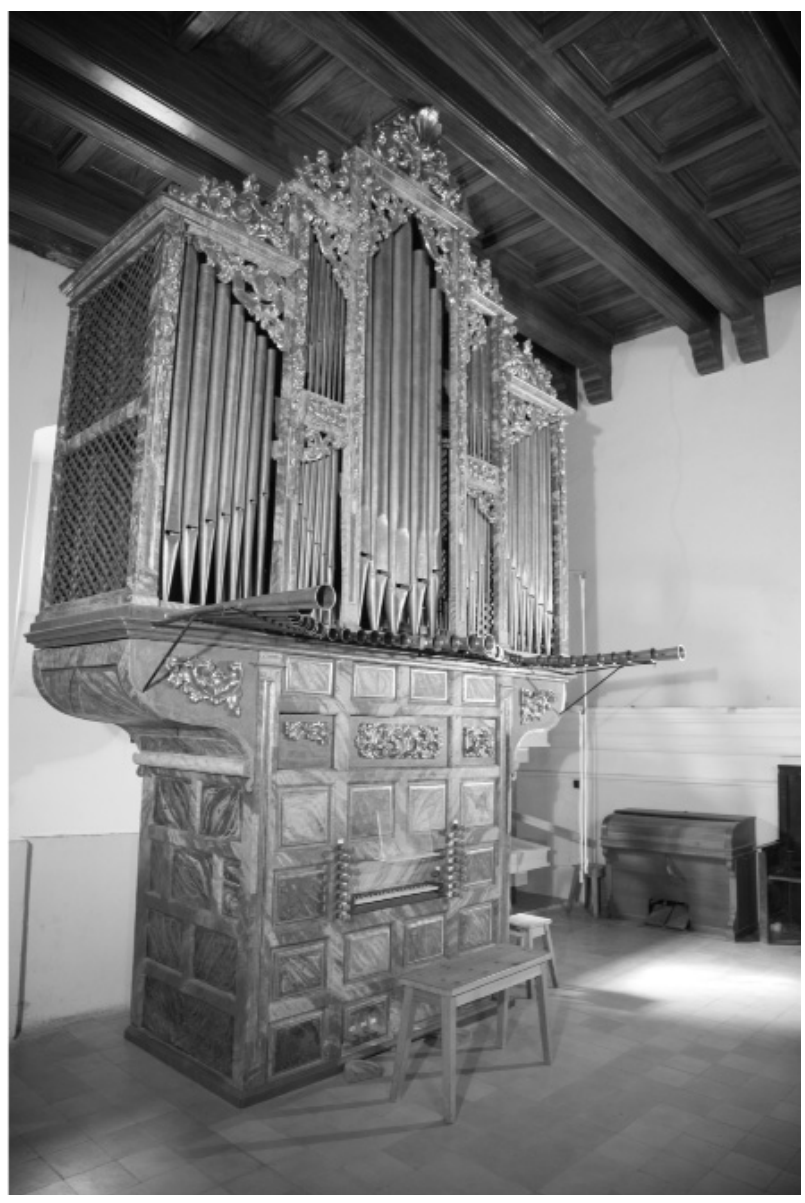

Figura 7. Órgano de la iglesia de Santa María del Castillo de Olmedo, anteriormente de Puras (José I. Palacios)

El auto del remate se rubricó el 17 de octubre de 1731, por don Manuel de Orilla y Estavillo, Visitador de la diócesis, Provisor y Vicario general de esta ciudad y del obispado de Ávila, por delegación al canónigo Guerrero. La obra se ajusta entre el párroco y el organero en 6.300 reales de vellón, incluida la caja ${ }^{153}$, que por entonces está inmerso en la obra de Hornillos (como podemos observar los precios eran similares entre los organeros de la época; sirva de ejemplo el de Pesquera de Duero, de 1726, ejecutado por Gabriel López Ortega, y cuyo coste con la caja ascendió a 6.438 reales) ${ }^{154}$.

153 Puras, Parroquia Ascensión de Nuestra Señora, Libro de Fábrica (1709-1796), AGDVa: f. 79 v.-80.

154 Pesquera de Duero, Parroquia San Juan Bautista, Libro de Cuentas de Fábrica (1678-1733), AGDVa, Caja nº. 2: s.f., y LAMA (1981): 285 y 412-413. Hemos tomado este órgano de Pesquera de Duero como referencia por ser coetáneo de Urarte, en 1726, y de similares 
Un legajo firmado por Felipe Urarte en Ávila, el 16 de octubre de 1733, nos describe la caja, que tendría dos pies y medio tiene de fondo, de ancho once pies y medio (1,93/3,40 $\mathrm{m}$ de ancho, $5 \mathrm{~m}$ de alto, y de fondo $1,03 \mathrm{~m})$, con siete castillos separados por pilastras con los tubos del Flautado (cinco cantantes y dos mudos), además de festones de talla, y una tarjeta por remate ${ }^{155}$. El mueble tiene grandes parecidos con la de la de Santa María de Pozaldez, aunque ésta es más alta y voluminosa que la de Olmedo, al haber sufrido reformas posteriores y colocado un tablón dorado para los conductos de la lengüetería de fachada. La base presenta la misma morfología, de cuarterones pintados y dorados, y las dos calles laterales van rematadas con angelotes en el caso de Pozaldez. El cartelón central es similar en los dos casos. También el material sufrió alteraciones y la adicción de la lengüetería de fachada unos años más tarde. Ha sido restaurado por el taller de Federico Acitores en el año 2006. La disposición es la siguiente, con la curiosidad de la doble quincena:

$\begin{array}{ll}\text { Flautado de 13 } & \text { Flautado de 13 } \\ \text { Octava } & \text { Octava } \\ \text { Nasarte en docena } & \text { Nasarte en docena } \\ \text { Docena clara } & \text { Docena clara } \\ \text { Quincena } & \text { Quincena } \\ \text { Tapadillo } & \text { Tapadillo } \\ \text { Lleno 4 h } & \text { Lleno 4 h } \\ & \text { Sexquiáltera } \\ & \text { Corneta real y de Ecos (conmu- } \\ & \text { tadas por estribos) } \\ \text { Címbala 4 h } & \text { Címbala 4 h } \\ \text { Bajoncillo } & \text { Clarín } \\ \text { Tres pisas: Tambor, Pajarillos y Ronco de Gaita. }\end{array}$

\section{CONCLUSIONES}

Felipe Urarte es un claro ejemplo de la época dorada de la primera época de la organería barroca en tierras castellanas, aunque él proviniera de un taller del norte peninsular de renombrada fama, como eran Viana (Navarra). Como tantos maestros itinerantes llenaron los templos del ámbito rural de instrumentos de contrastada calidad. Al mismo tiempo, le

características, aunque algunas partidas varían de uno a otro. Así, en Pesquera de Duero invierten 58 reales por los materiales y su caja, 514 reales del gasto del maestro, oficiales y caballería por el tiempo que permaneció en Pesquera, y 125 reales por traer los materiales, carbón para la cañutería y otros gastos menudos. En 1730 el organero de Peñafiel, Gabriel López, incorpora dos nuevos registros; al año siguiente está en La Pedraja del Portillo, y en 1735 en Villabañez.

155 Legajo 354, ADAv, Documento 12, Caja del órgano: s.f. reportó poder gozar de una posición inmejorable dentro del clero y las órdenes religiosas.

En la actualidad estamos en condiciones de poder diseñar el mapa de todas sus actuaciones a lo largo de los treinta y un años en que desarrolló el oficio profesional de maestro constructor de órganos, que van desde Soria a Zamora y de Palencia a Segovia, situando su centro y taller en Tordesillas, al que se incorpora su hermano en la década de los años treinta.

Los modelos que aportó responden a estereotipos de comienzo del setecientos, con varios planos sonoros, y con un desarrollo marcado de la lengüetería, frente al coro de nasardos, que permanecerá en uso hasta casi la mitad de la centuria. Casi todos los instrumentos que conocemos de Urarte son de tamaño pequeño y mediano, salvo el de Santa María de Tordesillas, con precios tasados que rondan entre los 4.000 y los 7.000 reales de vellón. En este órgano se muestra audaz, con una caja exuberante en decoración, una triple fachada sonora, y una amplia y variada lengüetería en "artillera", pero retardatario en el uso de un teclado de 42 notas en desuso, y que no aplica en el de Pozaldez. Por el contrario, en los más pequeños elimina la lengüetería de fachada, elemento que se hace imprescindible en la segunda mitad del siglo, como sucede en Olmedo.

\section{BIBLIOGRAFÍA}

Acitores, Federico, "La restauración del órgano de la parroquia de Santa María del Castillo de Olmedo", José Ignacio Palacios Sanz (coord.), Órganos restaurados, Valladolid, Diputación Provincial, 2008, vol. I: 121147.

Álvarez-Valdés y Valdés, Manuel, La extranjería en la historia del derecho español, Oviedo, Universidad de Oviedo, 1992.

Ara Gil, Clementina Julia y Parrado Del Olmo, Jesús María, Catálogo de la provincia de Valladolid. Antiguo Partido Judicial de Tordesillas, Valladolid, Diputación Provincial de Valladolid, 1980, tomo XI.

Ayarra Jarne, José Enrique, Historia de los grandes órganos de coro de la catedral de Sevilla, Madrid, Dirección General de Bellas Artes, Ministerio de Educación y Cultura, 1974.

Barbier Ramos, Elena, Le, La organería en la provincia de Palencia (1500-1800), Palencia, Institución Tello Téllez de Meneses, Diputación de Palencia, 2008.

Barrero Baladrón, José María y Graaf, Gerard, A. C., De, $E l$ órgano de Santa Marina la Real de León y la familia Echavarría, organeros del Rey, León, Universidad de León, Secretariado de Publicaciones, 2004. 
Bermejo, María, Restauración de la Caja del Órgano de la iglesia de Santa María. Tordesillas (Valladolid), (Inédito), 2011.

Castro Alonso, Manuel, de, Episcopologio vallisoletano, Valladolid, Tipográfica y Casa Editorial Cuesta, 1904.

Castro Toledo, Jonás, "Tordesillas en 1494, más o menos: una visión retrospectiva”, Celso Almuiña (coord.), Tordesillas 1494, Madrid, Sociedad V Centenario del Tratado de Tordesillas y Consejería de Cultura y Turismo de la Junta de Castilla y León, Ed. Electa, 1994: 155-156.

Cea Galán, Andrés, "La organería en la Andalucía barroca: Centros de actividad y circuitos de difusión", Congreso Internacional Andalucía Barroca, Alfredo José Morales Martínez (coord.), Sevilla, Junta de Andalucía, Consejería de Cultura, 2009, vol. 3: 259-266.

Donostia, José Antonio, "El órgano de Tolosa (Guipúzcoa), del año 1686", Anuario Musical, 10, (Barcelona, 1955): 121-136.

Fernández Torres, Eleuterio, Historia de Tordesillas (Ed. Facsímil), Valladolid, Institución Cultural Simancas, 1982.

Flórez Santiago, Virginia, Documentación histórica del actual patrimonio organístico. Propuesta metodológica para su catalogación y estudio, Valladolid (Trabajo de Investigación Tutelado, Inédito), Universidad de Valladolid, 2003.

García Chico, Esteban, "Documentos para el estudio del Arte en Castilla. Maestros de hacer órganos (Segunda parte)", Anuario Musical, XI (Barcelona, 1956): 195218.

García Chico, Esteban, Catálogo Monumental de la Provincia de Valladolid. Antiguo partido de Medina del Campo, Valladolid, Diputación Provincial de Valladolid, 1964, vol. IV.

http://www.proyectoclarin.com/001 Proyecto Clarin. php?idioma=ESP

Iglesia Ugarte, José Santos, de la, Los órganos en la Rioja, Logroño, Asociación Pro Música "Fermín Gurbindo" y Gobierno de La Rioja, 1991.

Iglesia Ugarte, José Santos, de la, Catálogo histórico documental de los órganos de Álava, Vitoria-Gasteiz, Diputación Foral de Álava, Departamento de Cultura y Euskera, 1997.

Jambou, Louis, "El órgano en la península ibérica entre los siglos XVI y XVIII. Historia y estética”, Revista de Musicología, vol. II, 1 (Madrid, 1979): 19-46.

Jambou, Louis, Evolución del órgano español. Siglos XVIXVIII, Gijón, Ethos-música, Serie Académica, Universidad de Oviedo, 1988, vol. I y II.
Jambou Louis, "La organería Vasco-Navarra hasta finales del siglo XVIII", José Manuel Azkue, Esteban Elizondo, y José María Zapirain (dir.), Órganos de Gipuzkoa, San Sebastián, Fundación Kutxa, 1998: 75-93.

Jambou, Louis, Voz "Ugarte, Felipe", Emilio Casares Rodicio (dir.), Diccionario de la Música Española e Iberoamericana, Madrid, S.G.A.E. 2002, vol. 10: 549.

Labeaga Mendiola, Juan Cruz, "La música en la parroquia de Santa María de Viana (Navarra), siglos XVI y XVII, Príncipe de Viana, 158-159 (Pamplona, 1980a): 203-250.

Labeaga Mendiola, Juan Cruz, "De organistas y organeros en Navarra en el siglo XVII", Príncipe de Viana, 160161, (Pamplona, 1980b): 507-560.

Labeaga Mendiola, Juan Cruz, "Organeros de Viana (Navarra) en La Rioja", Berceo, 102 (Logroño, 1982): 125131.

Labeaga Mendiola, Juan Cruz, "La música en la parroquia de San Pedro de Viana (Navarra)", en Cuadernos de Sección. Música, 2 (San Sebastián, 1985): 7-77.

Labeaga Mendiola, Juan Cruz, "Órganos y organistas de Sangüesa (Navarra)", Revista de Musicología, vol.9, 1 (Madrid, 1986): 57-96.

Labeaga Mendiola, Juan Cruz, "La música en la parroquia de Santa María de Viana (Navarra), siglos XVIII y XIX", Cuadernos de Sección. Música, 4, (San Sebastián, 1988): 35-81.

Labeaga Mendiola, Juan Cruz, "El taller de organeros de Viana, (Navarra), siglos XVII y XVIII", Cuadernos de Sección. Música, 5 (San Sebastián, 1991): 23-77

Labeaga Mendiola, Juan Cruz, "Organeros y órganos en Sangüesa", Príncipe de Viana, Año 57, 209 (Pamplona, 1996): 499-544.

Lama, Jesús Ángel, de la, El órgano en Valladolid y su provincia: Catalogación y estudio, Valladolid, Obra Cultural de la Caja de Ahorros Provincial de Valladolid, 1981.

Lama, Jesús Ángel, de la, El órgano barroco español.I. Naturaleza, Valladolid, Junta de Castilla y León y Asociación Manuel Marín, 1995a.

Lama, Jesús Ángel, de la, El órgano barroco español. II. Registros ( $1^{a}$ parte), Valladolid, Junta de Castilla y León y Asociación Manuel Marín, 1995b.

Lama, Jesús Ángel, de la, El órgano barroco español. El órgano barroco español. II. Registros ( $2^{a}$ parte), Valladolid, Junta de Castilla y León y Asociación Manuel Marín, 1995c.

Lama, Jesús Ángel, de la, El órgano barroco español. III. Registración, Valladolid, Junta de Castilla y León y Asociación Manuel Marín, 1995d. 
Lois Cabello, Joaquín, Memoria final de la restauración del órgano de la iglesia de Santa María de Tordesillas (Inédito), 2011.

Marco Martínez, Juan Antonio, El órgano histórico en la provincia de Guadalajara, Torrejón de Ardoz, Gráficas Dehon, 1990.

Marcos Villán, Miguel Ángel y Fraile Gómez, Ana María, Catálogo de la provincia de Valladolid. Antiguo Partido Judicial de Medina del Campo, Valladolid, Diputación Provincial de Valladolid, 2003.

Martín González, Juan José, Catálogo de la provincia de Valladolid. Antiguo Partido Judicial de Valladolid, Valladolid, Diputación Provincial de Valladolid, 1973, tomo VI.

Martín i Coll, Antonio, Tonos de Palacio y Canciones comunes, Julián Sagasta, (trans.), Madrid, Unión Musical Española, 1984.

Matesanz Del Barrio, José, "Los órganos de la epístola y del evangelio en la catedral de Burgos", Boletín de la Institución Fernán González, 207 (Burgos, 1993): 299-332.

Nieto Miguel, Ignacio, Órganos barrocos de la provincia de Valladolid, Valladolid, Diputación de Valladolid, 2009.

http://www.organaria.es (última consulta 19 noviembre de 2011).

Novísima recopilación de las leyes en España. Dividida en XII libros. Mandado formar por el señor don Carlos IV, Madrid, 1805, tomo II.

Palacios Sanz, José Ignacio, Órganos y organeros en la provincia de Soria, Soria, Colección "Temas sorianos", Diputación Provincial, 1994.

Palacios Sanz, José Ignacio, "Movilidad y circulación de maestros de capilla y organistas en la catedral de El Burgo de Osma (Soria)", Begoña Lolo Herranz (coord.), Campos interdisciplinares de la Musicología, Madrid, Sociedad Española de Musicología, 2001, vol. II: 901-929.

Palacios Sanz, José Ignacio, "Felipe Ugarte y la organería en la villa de Olmedo: El órgano de la parroquia de Santa María del Castillo", José Ignacio Palacios Sanz (coord.), Órganos restaurados, Valladolid, Diputación Provincial, 2008, vol. I: 75-119.

Parrado del Olmo, Jesús María, "Patronos y obras de arte en Santa María de Tordesillas", Boletín del Seminario de Arte y Arqueología, 56 (Valladolid, 1990): 518-541.
Pérez Iracheta, Rubén, "El órgano de Ezcaray”, Fayueta. Revista de Estudios Calceatenses, 2 (Santo Domingo de La Calzada, 2006): 35-42.

Reinoso Robledo, Luciano, Integración de la música y la arquitectura en España. El órgano histórico-artístico en Castilla y León: Segovia. Estudio historiográfico, musicológico y técnico. Catalogación, Madrid, Universidad Complutense de Madrid, 1991, tomo II y tomo III.

Rodríguez Suso, Carmen, "Notas sobre la organería en Vizcaya durante el s. XVIII. Aportación documental", Recerca Musicológica, 3 (Cerdanyola del Vallès, 1983): 137-172.

Rubio, Constancio, "Galería de oconenses ilustres", Valle de Ocón, 1 (Ocón, 2000): 20.

Saenz Terreros, María Victoria, "El órgano de Covarrubias: Nuevos datos sobre su historia", Boletín de la Institución Fernán González, 2 (Burgos, 1981): 281-290.

Sáenz De Ocáriz y Ruiz De Azúa, Matías, La música en los archivos de la Catedral de Santo Domingo de La Calzada. Siglos XVI al XIX, Logroño, Asociación ProMúsica "Fermín Gurbindo", 2001.

Sagaseta, Aurelio y Taberna, Luis, Órganos de Navarra, Pamplona, Gobierno de Navarra, 1985.

Salas Franco, María Pilar, "Aportación documental para el estudio de la organería riojana: El órgano de la iglesia de San Cosme y San Damián de Arnedo", Begoña Arrúe Ugarte (coord.), Historia del Arte en La Rioja Baja, ámbito y vínculos artísticos: La Rioja 8, 9 y 10 de octubre de 1993. IV Jornadas de Arte Riojano, Alfaro, Instituto de Estudios Riojanos, 1994: 47-96.

Saura Buil, Joaquín, Diccionario técnico-histórico del órgano en España, Barcelona, Consejo Superior de Investigaciones Científicas, 2001.

Torrente; Álvaro, "Cuestiones entorno a la circulación de los músicos catedralicios en la España moderna", Artigrama, 12, (Granada, 1996-1997): 217-236.

Zudaire Huarte, Claudio, "De organistas y organeros en Navarra en el siglo XVII", Príncipe de Viana, 160-161 (Pamplona, 1980), pp. 507-560.

Zudaire Huarte, Claudio, "El último órgano de Félix de Yoldi (1655-1695)", Revista de Musicología, VII-2, (Madrid, 1984): 351-367.

Zudaire Huarte, Claudio, "Testamento del organero Juan de Tabar (1634-1682)", Revista de Musicología, IX-2 (Madrid, 1986): 412-425. 
